\title{
The evolution of the brain, the human nature of cortical circuits, and intellectual creativity
}

\author{
Javier DeFelipe $e^{1,2,3 *}$ \\ 1 Instituto Cajal, Consejo Superior de Investigaciones Cientificas, Madrid, Spain \\ 2 Laboratorio Cajal de Circuitos Corticales, Centro de Tecnología Biomédica, Universidad Politécnica de Madrid, Madrid, Spain \\ ${ }^{3}$ Centro de Investigación Biomédica en Red sobre Enfermedades Neurodegenerativas, Madrid, Spain
}

\section{Edited by:}

Idan Segev, The Hebrew University of Jerusalem, Israel

\section{Reviewed by:}

Kathleen S. Rockland, Massachusetts Institute of Technology, USA

Ranulfo Romo, Universidad Nacional

Autónoma de México, Mexico

\section{*Correspondence:}

Javier DeFelipe, Laboratorio Cajal de

Circuitos Corticales, Centro de

Tecnología Biomédica, Universidad

Politécnica de Madrid, Campus

Montegancedo S/N, Pozuelo de

Alarcón, 28223 Madrid, Spain;

Instituto Cajal (CSIC), Avenida Doctor

Arce 37, 28002 Madrid, Spain

e-mail:defelipe@cajal.csic.es
The tremendous expansion and the differentiation of the neocortex constitute two major events in the evolution of the mammalian brain. The increase in size and complexity of our brains opened the way to a spectacular development of cognitive and mental skills. This expansion during evolution facilitated the addition of microcircuits with a similar basic structure, which increased the complexity of the human brain and contributed to its uniqueness. However, fundamental differences even exist between distinct mammalian species. Here, we shall discuss the issue of our humanity from a neurobiological and historical perspective.

Keywords: human nature, evolution, cortical circuits, brain size, number synapses, pyramidal neurons
Homo sum, humani nihil a me alienum puto

(I am a human being, and therefore, nothing human is strange to me)

Publius Terentius Afer (195/185-159 BC)

\section{INTRODUCTION}

The nervous system has evolved over millions of years, generating a wide variety of species-specific brains and behavioral capacities. For example, the production and appreciation of art seems to be a uniquely human attribute, a recently acquired cognitive capacity in the genus Homo. Almost everything that the human being creates has a touch of art, although we do not need beauty or an esthetic perception to survive but rather, it just simply produces intellectual pleasure. The same occurs with other mental activities, like reading a book or listening to music. It seems obvious that only anatomically modern humans (i.e., Homo sapiens) can be behaviorally modern, capable of creating symbolic objects. Maybe this is when we discovered the world of ideas and created the concept of the soul or spirit. From that moment, the relentless pursuit to define where such a trait is forged began, resulting in the so called "mind-body problem." Of the numerous images available, we have chosen two here to illustrate in distinct ways the relationship between the mental and the physical worlds, both suggesting a separation between the two entities. Figure 1 shows the painting Fray Pedro de San Dionisio by Francisco de Zurbarán, 1598-1664, and a sculpture of Don Quixote present at the Museum of Modern Art in Mexico.

Perhaps modern neuroscience has contributed most in this field by addressing the issue of mental processes from a biological standpoint. Nevertheless, it is striking how little influence this neuroscientific knowledge has had on society due to the failure in conciliating the relationship between the brain and our humanity. It is commonly thought that the increase in complexity as our brain has evolved is a product of the addition of microcircuits with a similar basic structure that incorporate only minor variations. Indeed, speciesspecific behaviors may arise from very small changes in neuronal circuits (Katz and Harris-Warrick, 1999). However, we will see that the human cerebral cortex has some distinctive circuits that are most likely related to our humanity. In addition, there are some erroneous popular beliefs regarding the relationship between brain size, evolution, and intellectual capabilities, and regarding the patterns of convolutions and the external morphology of the brain. Here, I shall deal with these topics with the aid of some historical notes.

\section{BRAIN SIZE AND INTELLECTUAL CAPABILITIES}

The absolute brain size of hominids has tripled since the Pliocene age (from an average of $450 \mathrm{~cm}^{3}$ in Australopithecus to $1,345 \mathrm{~cm}^{3}$ in H. sapiens: Holloway, 1996). Throughout evolution, human encephalization can be expressed quantitatively by an "encephalization quotient" (Jerison, 1973). This ratio is calculated on the basis of brain and body weight relative to the expected brain weight, taking the cat as the "standard" for mammals $(\mathrm{EQ}=1)$. Thus, EQ values of less than or more than 1 indicate a relative brain size that is below or above what would be expected. Using this measure, EQs of 2.5 and 7.5 have been calculated in fossil specimens of Australopithecus afarensis (3.1-3.6 million years old, probably the immediate predecessors of the genus Homo) and Homo neanderthalensis (30,000 years), respectively (Marino, 1998). Modern human has the highest EQ of the mammals, between 7.4 and 7.8 , and accordingly, it has often been assumed that the EQ is a good predictor of intelligence. However, many exceptions have been found 
since dogs are relatively intelligent creatures compared to squirrels but their EQs are similar (1.1 and 1.2, respectively). Likewise, New World capuchin monkeys have higher EQs (2.4-4.8) than chimpanzees (2.2-2.5) and gorillas (1.5-1.8) but they are less intelligent (Roth and Dicke, 2005).
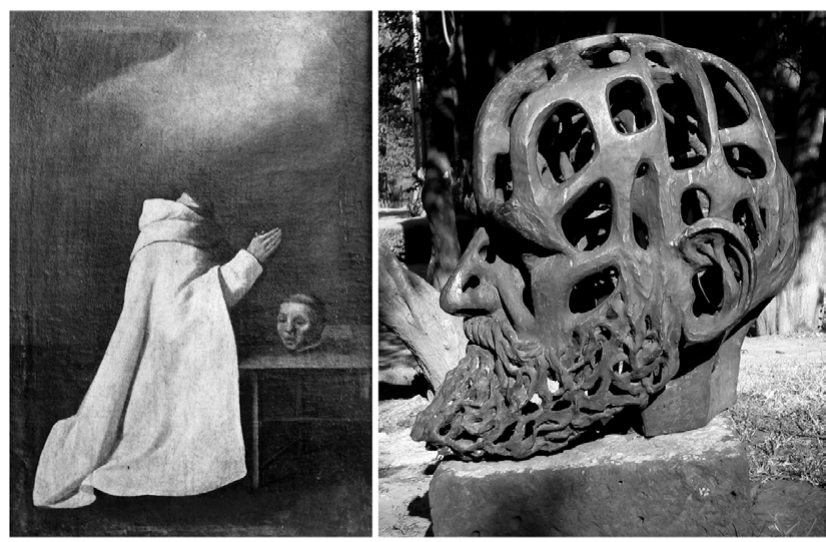

FIGURE 1 |The mind-body problem. Left: Fray Pedro de San Dionisio, painted by Francisco de Zurbarán (1598-1664). (C) Fundació Institut d'Art Hispanic Amatller. Arxiu Mas. Right: Don Quixote, Museum of Arte Moderno in Mexico. These images are examples of the separation between the mental and the physical worlds. The saint levitates while praying, and his head is separated from his body; Don Quixote appears reflective, with an empty head.

\section{THE BRAINS OF "GREAT MEN"}

In the nineteen and early twentieth centuries, the marked increase in human brain size during evolution, its relationship with higher brain functions (Figure 2) and the large differences in intellectual abilities between individuals, provoked studies to determine whether the brains of people with higher intellectual abilities could be distinguished by anatomical features of the brain (size or shape). At first glance, the significance of the differences in brain size is not clear in our species. For example, the English poet Lord Byron (1788-1824) seems to have a great brain, not only due to the quality witnessed by his writings but also, given his enormous brain, weighing $2.238 \mathrm{~kg}$. Oliver Cromwell (1599-1658), protector of the Republic of England, also had a brain that weighed between 2.233 and $2.330 \mathrm{~kg}$, whereas the French writer Anatole France (18441924), who won the Nobel Prize for literature in 1921, had a brain that weighed only $1.100 \mathrm{~kg}$. The great Swedish neuroanatomist and histologist Gustav Magnus Retzius (1842-1919) was particularly interested in the possible relationship between brain size and intelligence. In view of the negative results of the studies into brain morphology, and due to Retzius's interest in determining whether the brain of people with superior intellectual capacities might be distinguished by means of special anatomical characteristics, together with the physiologist Tigerstedt, Retzius proposed that their colleagues donate their brains for research (Spitzka, 1907). However, the forms for brain donation were only signed by Retzius and Tigerstedt. Other more successful initiatives established societies

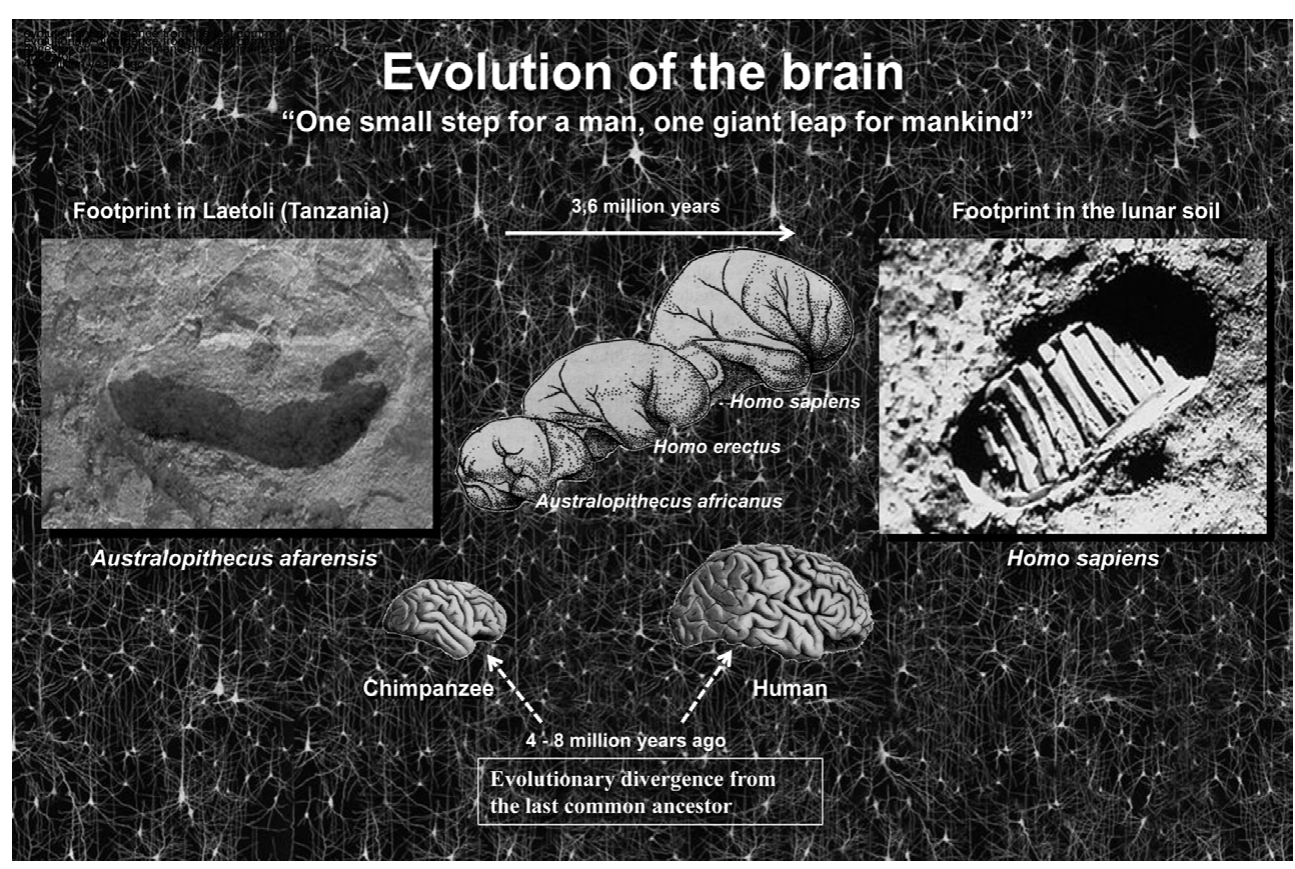

FIGURE 2 | One small step for a man, one giant leap for mankind (Neil Armstrong). Left, photograph of the footprint left approximately 3.5 million years ago by $A$. afarensis, probably the immediate predecessor of the genus Homo, in Laetoli (Tanzania). Right, footprint in the lunar soil made by the astronaut Neil Armstrong (Apollo 11, July 21, 1969), the first person ever to set foot on the Moon. In a relatively short period of time we have gone from taking the first steps upright in Africa to walking on the Moon. How was this possible? While the brain has certainly increased in size during evolution it is not clear that this is the sole cause. Thus, the key question is whether the increase in the number of cortical circuits or rather changes in these circuits has been the driving force behind humans' rapid development? The schemes of the size and shape of the brains (fossil endocranial casts) of the Australopithecus africanus, Homo erectus, and Homo sapiens were taken from Bermúdez de Castro (2002). 
or brain banks, including the American Anthropometric Society (established in 1889), so that the brains of eminent personalities from the fine arts, science, politics, music and literature could be analyzed by the scientific community. Spitzka, who was one of the founders of this society, doubted that the extremely high weights of the brains of Lord Byron and Cromwell were true. However, the weights of the brains of over a hundred famous people that he carefully studied ranged from 2.012 to $1.198 \mathrm{~kg}$ (Figure 3).

At the top of Spitzka's list was the Russian novelist Ivan Turgenev (1818-1883), author of the famous book "Fathers and Sons," while interestingly, the smallest brain was that of Franz Joseph Gall (1758-1828), one of the fathers of phrenology together with Johann Christoph Spurzheim (1776-1832). According to this doctrine, each mental faculty was located in a specific part of the cerebral cortex, the size of which was directly related to the development of such capacities, and that size could be revealed by the external configuration of the skull. Yet what about Gall at the foot of the list? There are other publications on normal people with very small brains, such as the case of Daniel Lyons who died in 1907 at the age of 41 years. Daniel was a person with no special features, with a normal body weight and of normal intelligence, although his brain weighed no more than $680 \mathrm{~g}$ (Wilder, 1911). Thus, it appears that a difference of almost $50 \%$ of brain mass, with its billions of neurons and syn- apses, may have no functional significance in terms of intelligence. If it is not brain size that determines whether a person is adept in music, painting, or literature, then it is probably the individual pattern of connections. To be more precise, both the quantitative and qualitative characteristics of connections are likely to influence intelligence, including the number of connections between particular functional groups of neurons, their molecular, and physiological characteristics, etc., which in turn depend on the genetic background and on the influence of the environment (DeFelipe, 2006; Figure 4).

\section{BRAIN SIZE AND THE ORIGIN OF HUMAN CULTURE}

Because the brain does not fossilize, anthropological studies into the intellectual capacity of the brain of our ancestors are restricted to examining the tools that they created. Thus, 1.8 million years ago, Homo erectus was able to create the first bifacial tools, suggesting that they had a greater cognitive capacity than Australopithecus. Homo heidelbergensis, existed 650,000 years ago and had a larger brain (cranial capacity of $1,350 \mathrm{~cm}^{3}$ ) than $H$. erectus (brain volume between 800 and $1,200 \mathrm{~cm}^{3}$ ). This species was capable of producing very symmetrical bifaces (with multiple uses including cutting skin, meat, or woodworking), as well as some tools from the flints, such as arrow or spearheads and scrapers for wood, bone, and

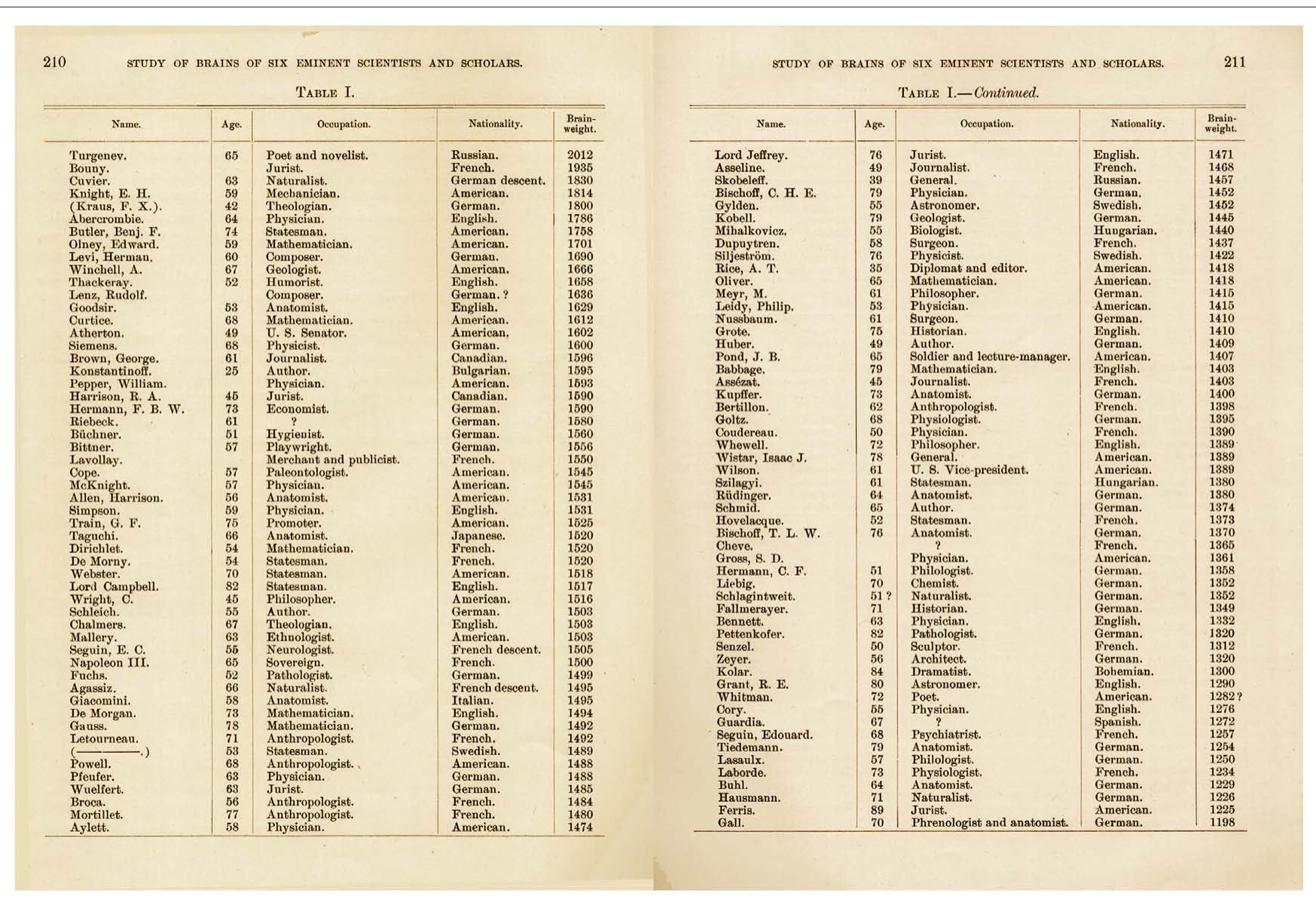



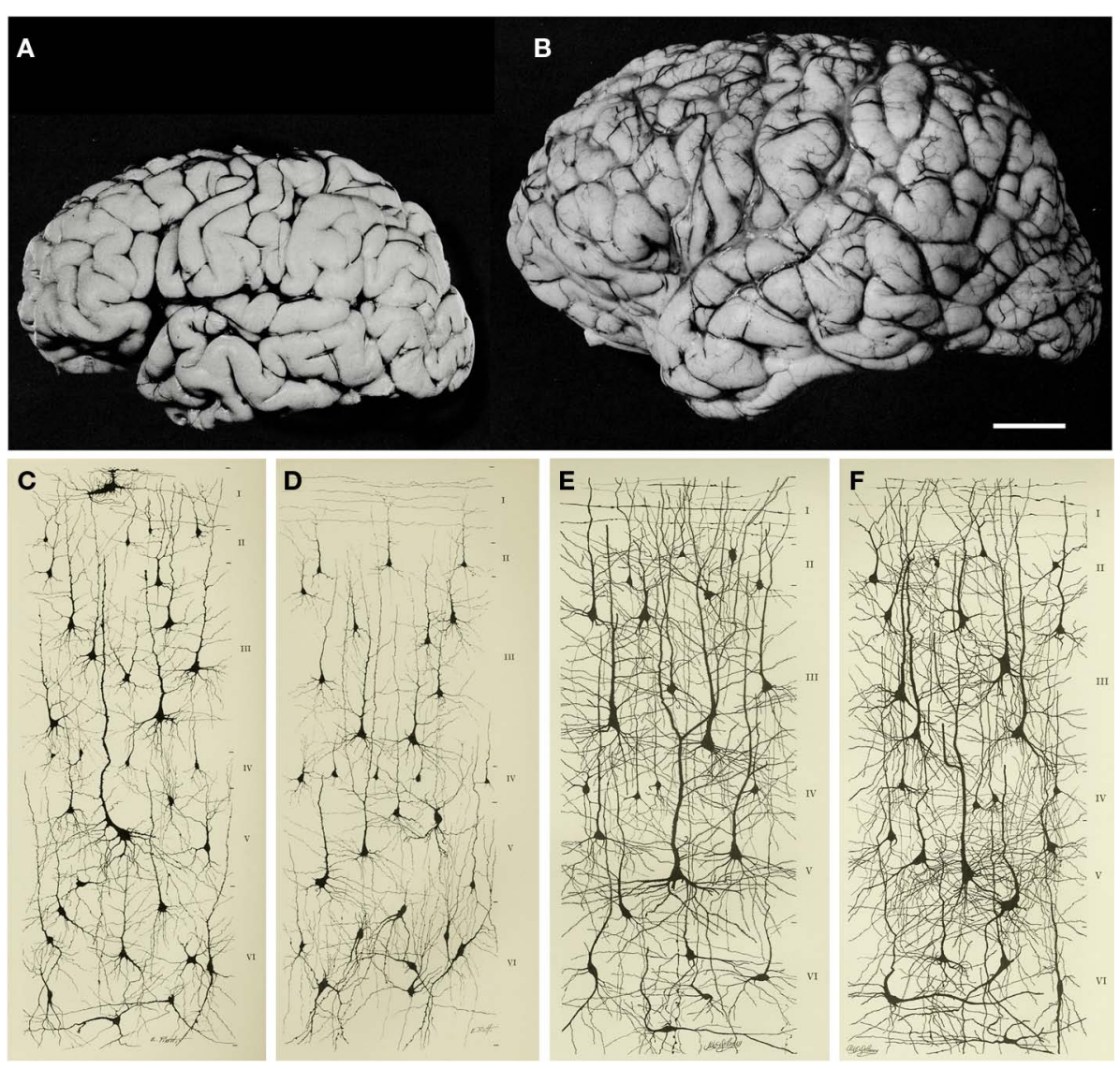

FIGURE 4 | Increase in brain size and the maturation of cortical circuits. The maturation of mental processes and motor skills is associated with an approximately fourfold enlargement in brain size. (A,B) photographs of the brains of a 1-month and 6-year-old-child. This increment is accompanied by a dramatic development in the complexity of the neuronal processes, which in turn is influenced by the genetic background and the environment. This increase in the complexity is clearly evident in the drawings of Golgi stained cortical neurons from the cerebral cortex of a 1-month [(C) "pars triangularis of gyrus frontalis inferior"; (D) "orbital gyrus"] and 6 year [(E), "pars triangularis of gyrus frontalis inferior"; (F) "orbital gyrus"] old child. Adapted from Conel and Le (1941, 1967). Scale bar for (A,B): 2 cm. horn, pioneering this technique. It is also likely that fire was first used at this time and that its use gradually spread. The use of fire represented an improvement in quality of life and adaptation to the environment, enabling diet to become more varied by cooking and improving resistance to the cold, as well as contributing to greater social interaction and to the development of communication (Holloway, 1996). Therefore, about 500,000 years ago modern cognitive abilities began to emerge.

The dominant view on the origin of human culture is that modern humans originated in Africa about 200,000 years ago, before spreading to the rest of the planet over the past 100,000 years (McDougall et al., 2005; Campbell and Tishkoff, 2008; Conard, 2010). It is believed that humans either suddenly (hypothesis of the model known as "human revolution") or gradually acquired their cultural nature in becoming modern man. Those in favor of the "human revolution" hypothesis base their argument on the fact that something like a technological, artistic, and behavioral explosion occurred 40,000-50,000 years ago, associated with numerous findings that suddenly and almost simultaneously appeared across the Old World (e.g., sophisticated cutting utensils, musical instruments, ornaments, figurative art, specialized hunting, use of water resources, evidence indicating the use of pigments, etc.). However, scientists argue that cognitively modern human behavior appeared thousands of years earlier in Africa than in Europe, due to the discovery of much older objects with incisions forming geometric patterns (Mcbrearty and Brooks, 2000). In fact, the discovery of the engraved ochre pieces at Blombos Cave in South Africa (Henshilwood et al., 2002, 2009), and the incised ostrich egg shells in Diepkloof Rock Shelter (Texier et al., 2010), appeared dozens of thousands of years prior to any similar pieces in Europe (that are 30,000-40,000 years old whereas some of the engraved objects found at Blombos are dated to 75,000-100,000 years: Figure 5). Hence, cultural and behavioral evolution would appear to have been gradual, originating in Africa before it was later exported to other regions of Europe and Asia.

We present some examples of the development of human artistic creativity (Figure 6): the Venus of Tan-Tan, the Lowenmensch ("lionman") of Hohlenstein-Stadel, the Venus of Willendorf and the David of the artist Michael Ángel (1475-1564). The Venus of TanTan is female figure and it has been estimated to be between 300,000 and 500,000 years of age. Some anthropologists hold that this object was modified deliberately to adopt an anthropomorphous form, 

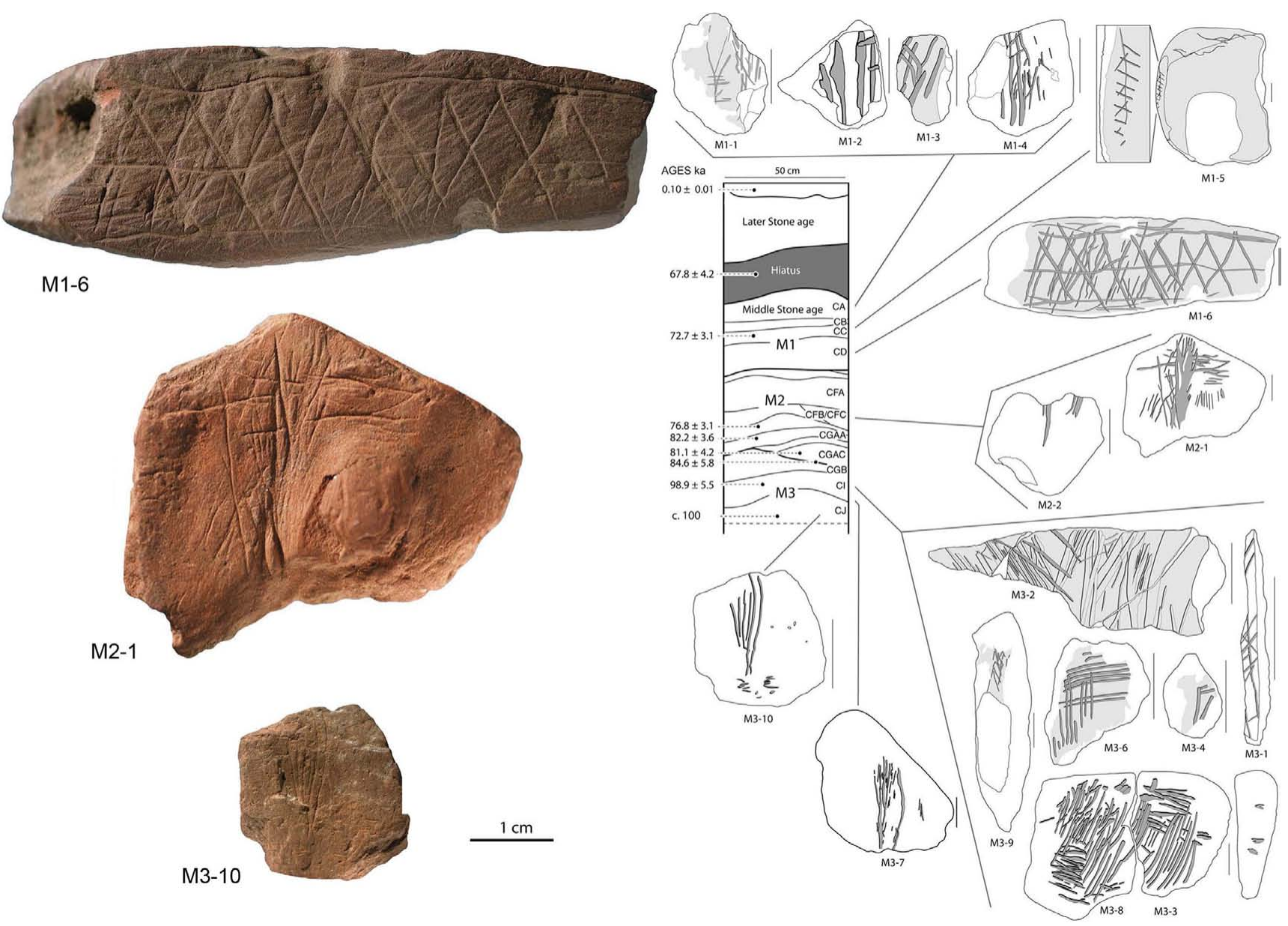

M1-6
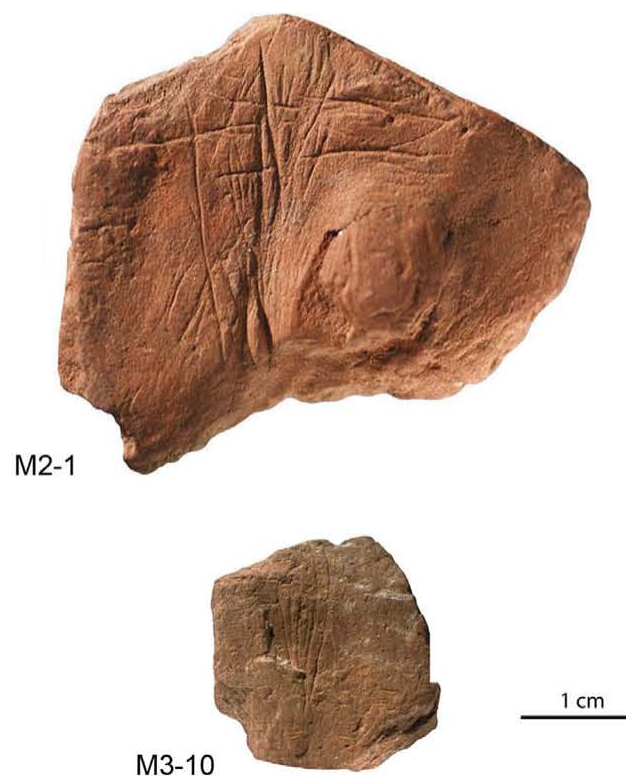

FIGURE 5 | Middle Stone Age engravings from South Africa. Photos and tracings of pieces M3-10, M2-1, and M1-6 from the Blombos Cave. In the drawing of the center is shown the stratigraphy and ages of Blombos Cave deposits. Adapted from Henshilwood et al. (2009).

whereas others are skeptical and believe that it is an object created by accident. The debate focuses on that fact that if it really is an object of art then it could not have been created by our species, since we appeared in Africa later, approximately 200,000 years ago. The author would probably have been $H$. heidelbergensis, considered by some anthropologists as the common antecessor of the Neanderthals and of modern humans (Balter, 2009; Klein, 2009). This would be contrary to the commonly accepted idea that only the anatomically modern humans (i.e., Homo sapiens) can be behaviorally modern, capable of creating symbolic objects. As we have seen above, the carved ochre pieces and ostrich egg shells indicate that modern human's symbolic expression dates back around 100,000 years. Indeed, pieces of undoubted artistic expression such as the lionman - which represents a mythical figure with the body of a man and a lion's head - and the Venus of Willendorf - which represents a nude woman, with her head covered with braids or with a hood - are only around 35,000 and 25,000 years old, respectively. These objects are of extraordinary interest, since they required highly developed artistic creativity, besides great technical skill and symbolic imagination, identical to that held by modern humans. The David - a sculpture considered
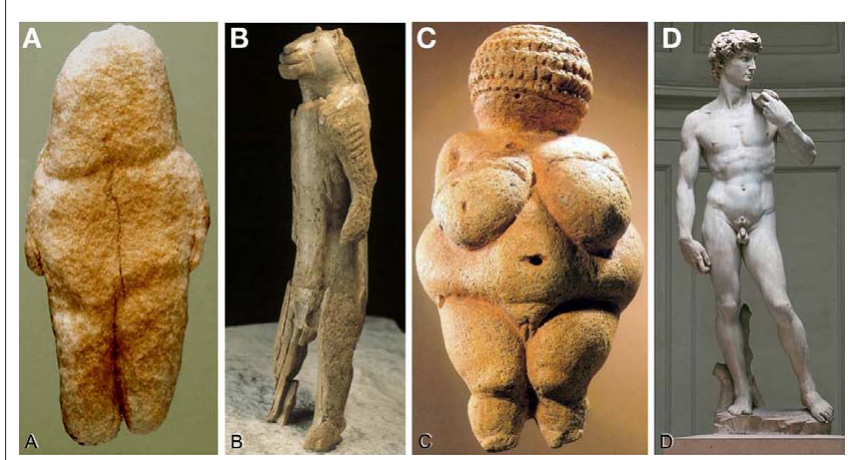

FIGURE 6 | Development of artistic creativity. Photographs of the Venus of Tan-Tan [6 cm in height, Morocco (A), the lionman of Hohlenstein-Stadel [29.6 cm, Germany (B), the Venus of Willendorf [11.1 cm, Austria (C), and David of Michelangelo [517 cm, created from a single block of marble between the years 1501 and 1504 (D). Taken from DeFelipe (2010a).

as one of the masterpieces of the Renaissance - is an example of the exceptional technical capacity and symbolic imagination that a human being can achieve. 
It is important to bear in mind that for our brain to be capable of developing these skills, cultural transmission, and education are critical. This has been clear since the time of the Ancient Greek philosophers and in fact, the physician and philosopher Juan Huarte of San Juan (1529-1588) published his classic book Examen de ingenios para las ciencias in 1575, in which he included the following interesting thought:

$[\ldots]$ in two or three years a human being learns all that his [ancestors] did in two thousand years. Indeed, if man had to acquire such knowledge by experience, it would be necessary to live three thousand years and by experimenting with medicines, he would first kill an infinite number of men before defining their qualities. However, this could be avoided by reading the books of rational and experienced doctors who warn in writing of what they found during the course of their lives.

For example, the contributions of Mozart, Einstein, or Picasso would not have been possible if they had not been born in the cultural moment in which they were. How many thousands of geniuses of the arts and of the sciences might have arisen over 200,000 years, when humans were anatomically modern, if they had had the cultural tools and the intellectual atmosphere available at present? Thanks to our capacity to learn through observation or interaction with other individuals, after a Picasso many Picassos would have arisen. Thus, in the next part I shall deal with the question of how the brain evolved to gain such capacities.

\section{THE HUMAN NATURE OF CORTICAL CIRCUITS: COMPARATIVE STUDIES}

Since the brain is composed of different functional units whose size may vary depending on species-specific behavior, one approach to analyze how the brain evolves is to study the allometric relationship of parts of the brain to overall brain size (Jerison, 1973; Finlay and Darlington, 1995; Barton and Harvey, 2000; Clark et al., 2001; de Winter and Oxnard, 2001). However, it is not clear what should be compared and how, nor what statistical tools are most appropriate to estimate each parameter or to test the hypotheses with the interspecies data (Yopak et al., 2010). Indeed, different conclusions may be reached even when comparative studies are performed using the same volumetric data (Clark et al., 2001; Kaas and Collins, 2001; de Winter and Oxnard, 2001; Barton, 2002; Sultan, 2002). Furthermore, there is remarkable variability in brain size among different mammalian species (Figure 7). This variation ranges from a brain weight of about $0.060 \mathrm{~g}$ for the insectivorous white-toothed pygmy shrew (Suncus etruscus, 2-3 g body weight: this mammal, together with the bumblebee bat Craseonycteris thonglongyai with a body weight of $2 \mathrm{~g}$, represents the smallest of mammals that exists on Earth) to up to $9.200 \mathrm{~kg}$ for the brain of the sperm whale (Physeter macrocephalus: 50,000 kg body weight). The brain of the blue whale (Balaenoptera musculus; 100,000 kg body weight), the largest animal on Earth, weighs $6.900 \mathrm{~kg}$, similar to the $6 \mathrm{~kg}$ that the brain of the Indian elephant weighs (Elephas indicus), despite having a 20 -fold lighter body weight $(5,000 \mathrm{~kg})$ than the blue whale. By contrast, the gorilla (Gorilla gorilla) and striped dolphin (Stenella coeruleoalba) have a similar body weight (gorilla, $160 \mathrm{~kg}$, dolphin, $150 \mathrm{~kg}$ ), although the gorilla's brain weighs only $500 \mathrm{~g}$ while that of the dolphin is $1.200 \mathrm{~kg}$.
However, despite this variability in brain size, the thickness of the cerebral cortex varies relatively little between brains of different sizes, and the variation observed within a given brain is similar to that found between species of different brain size (Figure 8). For example, the thickest cerebral cortex is represented by the human motor cortex, which can reach $4.5 \mathrm{~mm}$, while in the depths of the fissures it may only be $1 \mathrm{~mm}$ thick. The thickness of the frontal cortex of the dog is $0.8 \mathrm{~mm}$, while its parietal cortex is $1.6 \mathrm{~mm}$. The cerebral cortex of the pygmy shrew has a thickness of $0.4 \mathrm{~mm}$, while in whales, which have a brain that weighs several thousand times more than that of the pygmy shrew, much of the cerebral cortex is less than $2 \mathrm{~mm}$ thick. Furthermore, the appearance of the cellular components in Nissl-stained sections is generally similar in all cortices. All these observations suggest that increased brain size was the main development during evolution. However, we will see in the next sections that there are a number of findings showing this concept to be an oversimplification since there are significant structural changes, but interestingly, these studies have passed largely unnoticed.

\section{THE NEOCORTEX}

The appearance of a highly complex multi-laminated cortex, the "neocortex" is another crucial event during the evolution of the mammalian telencephalon. This cortical region is the most human part of the nervous system because it is the brain structure whose activity is directly related to the emergence of those capacities that distinguish humans from other mammals. Thanks to the neocortex we can perform such extraordinary and highly complex tasks as writing a book, compose a symphony, or invent the computer. Yet, what is special about the human cerebral cortex is a longstanding question in neuroscience. Indeed, this critical issue was already nicely expounded by Santiago Ramón y Cajal (1852-1934) in Recuerdos de mi Vida (Cajal, 1917):

At that time, the generally accepted idea that the differences between the brain of [non-human] mammals (cat, dog, monkey, etc) and that of man are only quantitative, seemed to me unlikely and even a little offensive to human dignity [...] language, the capability of abstraction, the ability to create concepts and finally, the art of inventing ingenious instruments [...] do [these facets] not seem to indicate (even admitting fundamental structural correspondences with the animals) the existence of original resources, of something qualitatively new which justifies the psychological nobility of Homo sapiens? Microscope at the ready, I then launched with my usual ardor to conquer the supposed anatomical characteristic of the king of Creation, to reveal these enigmatic strictly human neurons upon which our zoological superiority is founded.

However, while many aspects of cortical organization are maintained during mammalian evolution, some of the structural features are not unique to mammals, such as the laminar organization. For example, a well developed three-layer cortex, which is typically found in the mammalian olfactory cortex and hippocampus, is also present in the telencephalon of reptiles (Figure 9). Likewise, birds and mammals not only share many behavioral and cognitive traits (Byrne, et al., 2004; Couzin, 2009), but it was recently shown that a columnar functional organization exists in the auditory 


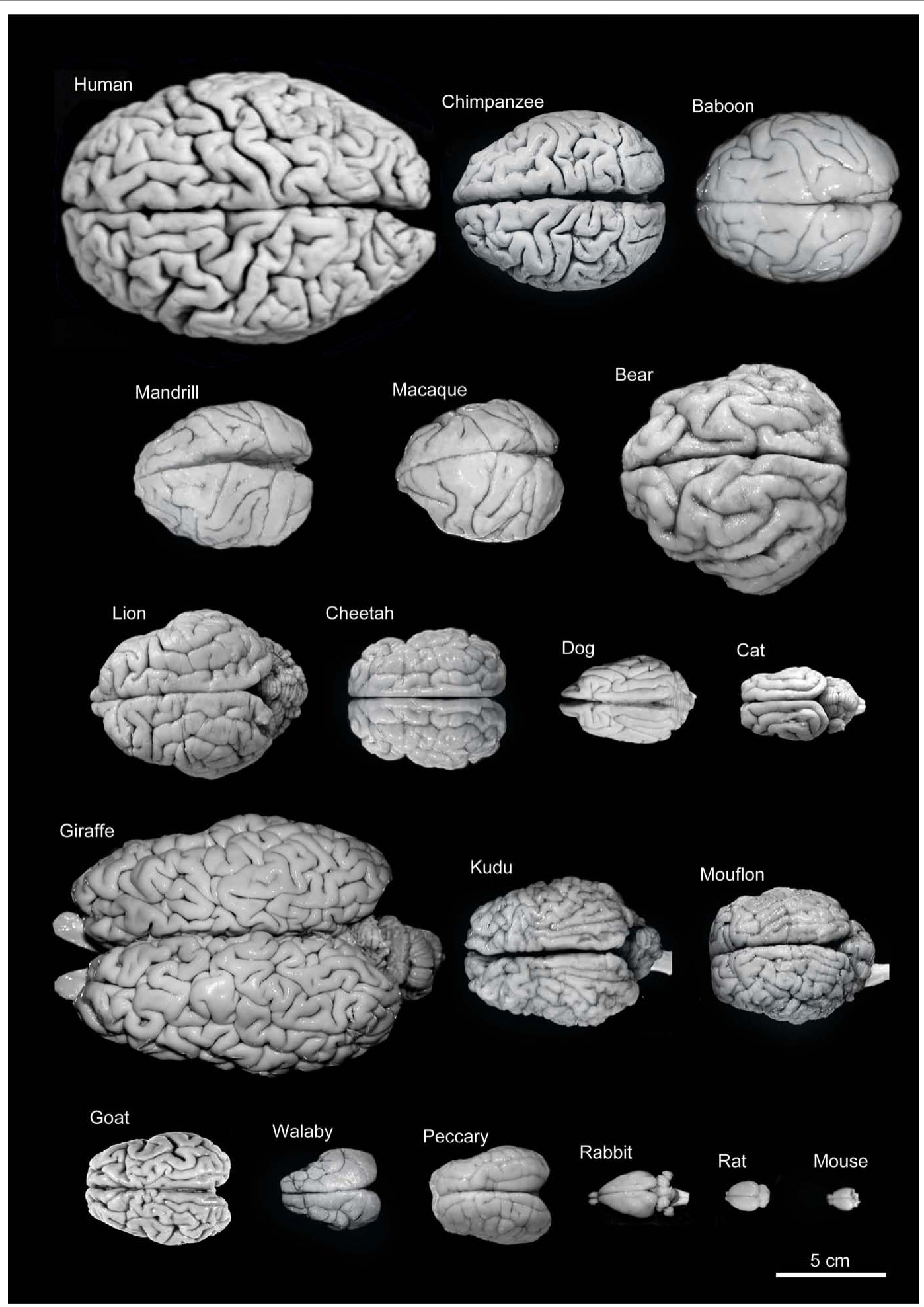

FIGURE 7 | Variability of brain size and external topography. Photographs and weights of the brains of different species. Primates: human (Homo sapiens, $1.176 \mathrm{~kg}$ ), chimpanzee (Pan troglodytes, $273 \mathrm{~g}$ ), baboon (Papio cynocephalus, 151 g), mandrill (Mandrillus sphinx, 123 g), macaque (Macaca tonkeana, $110 \mathrm{~g}$ ). Carnivores: bear (Ursus arctos, $289 \mathrm{~g}$ ), lion (Panthera leo, $165 \mathrm{~g}$ ), cheetah (Acinonyx jubatus, $119 \mathrm{~g}$ ), dog (Canis familiaris, $95 \mathrm{~g}$ ), cat (Felis catus, 32 g). Artiodactyls: giraffe (Giraffa camelopardalis, 700 g), kudu
(Tragelaphus strepsiceros, 166 g), mouflon (Ovis musimon, 118 g), ibex (Capra pyrenaica, $115 \mathrm{~g}$ ); peccary (Tayassu pecari, $41 \mathrm{~g}$ ). Marsupials: wallaby (Protemnodon rufogrisea, $28 \mathrm{~g}$ ). Lagomorphs: rabbit (Oryctolagus cuniculus, $5.2 \mathrm{~g}$ ). Rodents: rat (Rattus rattus, $2.6 \mathrm{~g}$ ), mouse (Mus musculus, $0.5 \mathrm{~g}$ ). The chimpanzee brain was kindly supplied by Dr. Dean Falk. The rest of non-human brains were from material used in Ballesteros-Yánez et al., 2005). Scale bar: $5 \mathrm{~cm}$. 


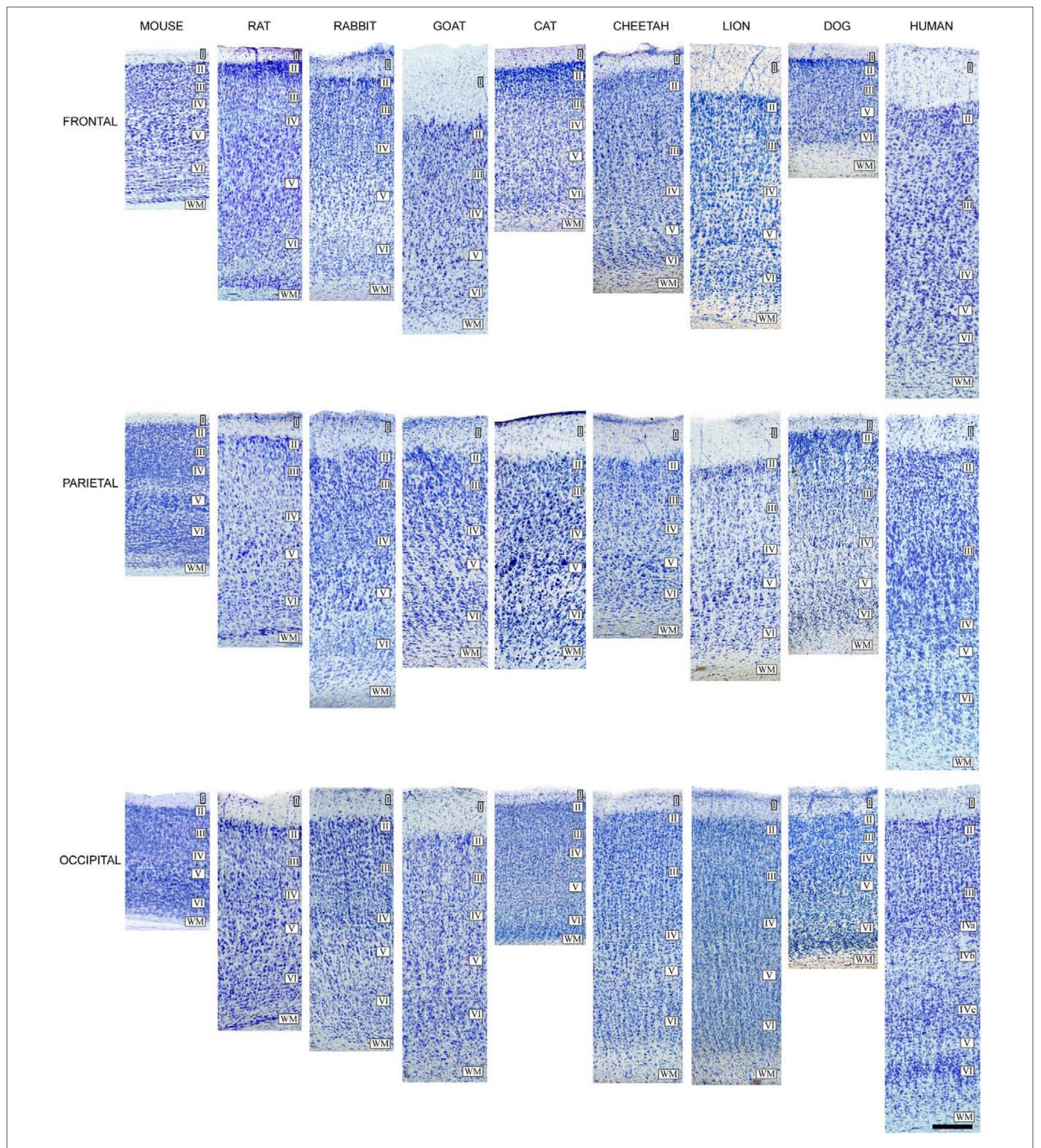

FIGURE 8 | Cytoarchitectonic differences in the mammalian cortex. Photomicrographs from $100 \mu \mathrm{m}$ thick Nissl-stained sections showing some cytoarchitectonic differences between frontal, parietal, and occipital cortical areas of the human (areas 10, 3b, and 17, respectively) and several mammals. Scale bar: $250 \mu \mathrm{m}$. Adapted from Ballesteros-Yánez et al. (2005).

telencephalon of an avian species (Gallus gallus), which has been proposed to be similar to the columnar organization of the neocortex (Wang et al., 2010). Nevertheless, columns are not an obligatory cortical feature and they can be found in non-cortical structures (Rockland, 2010). In turn, the neocortex of all species contains a set of elements similar to that of any other part of the brain (i.e., 


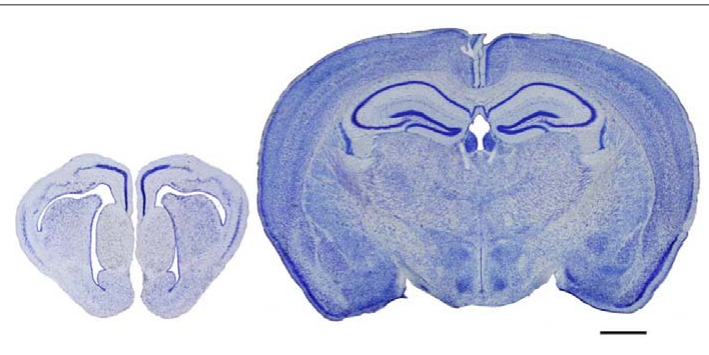

FIGURE 9 | Evolutionary development of the cortex. Photomicrographs of coronal sections (100 $\mu \mathrm{m}$ thick Nissl-stained sections) of the telencephalon of a reptile (gecko, left) and a mammal (mouse, right), illustrating the evolutionary development of the cortex. Scale bar: $1000 \mu \mathrm{m}$.

projection neurons and interneurons, extrinsic and intrinsic nerve fibers, astrocytes, oligodendrocytes, microglia, and blood vessels). The physiological properties, type of synapses, neurotransmitters and neuroactive peptides, receptors and ion channels, and other compounds generally expressed by cortical neurons are not unique to the neocortex, but they are found throughout the brain (DeFelipe et al., 2002). Thus, one of the primary questions in neuroscience is what neural substrates make a human being human?

\section{SPECIES-SPECIFIC VARIATIONS IN CORTICAL MICROSTRUCTURE Number of neurons per column and cytoarchitectonic variations}

A highly influential article on the evolution and structure of the neocortex has been published (Rockel et al., 1980) in which the number of cells within small strips of different functional neocortical areas was calculated (motor, somatic sensory, area 17, frontal, parietal, and temporal) in several species (mouse, rat, cat, monkey, and man). Despite the differences in the size of the brains, the number of neurons through the depth remains constant, except in area 17 of primates where there are 2.5 times more neurons. This study strongly supports the idea that differences in cytoarchitecture and function reflect differences in connections. However, using more accurate quantitative methods, like the unbiased stereological method of the disector introduced in 1984 (Sterio, 1984), several authors could not confirm the findings of Rockel et al. (1980) in the rat and cat (Beaulieu and Colonnier, 1989; Beaulieu, 1993; Skoglund et al., 1996), or that each cortical unit contains a similar number of neurons in other species (Haug, 1987; Stolzenburg et al., 1989; DeFelipe et al., 2002).

There are many exceptions to the classical division of the neocortex into six layers. For example, layer IV is not present in the motor and premotor areas of many species. More than six layers are recognized in the primary visual cortex of primates, and some of the numbered layers can be clearly divided or merged in other cortical areas of primates and non-primates (DeFelipe et al., 2002). A well-known variation in the disposition of neurons is the barrel cortex of rodents in which the barrels consist of layer IV aggregates of neurons. This is frequently considered as an exception but many other cytoarchitectonic variations based on differential neuronal clustering also exist. In this regard, we should bear in mind that there are over 4,500 mammalian species, yet the vast majority of studies of cortical microstructure have been performed in the mouse, rat, cat, and monkey, and to a lesser extent in humans. This is why researchers are often amazed, not only by the great variety of sizes, external topographies, and patterns of convolutions of the mammalian brain (Figures 7 and 10), but also by the variety of different microscopic cortical structures observed in the neocortex of some "exotic" species such as elephants, pigmy shrew, manatees, platypus, dolphins, giraffes, or apes (e.g., Haug, 1987; Glezer et al., 1988, 1993; Reep et al., 1989; Stolzenburg et al., 1989; Hof et al., 1999, 2000; DeFelipe et al., 2002; Preuss and Coleman, 2002). Even at a glance, there are clear differences in the neuron density and cytoarchitectonic organization in Nissl-stained sections when comparing some species such as those shown in Figure 11. Another interesting example is the presence of clumps of neuronal cell bodies in layer VI of the cerebral cortex of dugongs, which Dexler (1913) called "basal Rindenkerne" (basal cortical nuclei). These cellular aggregates have also been found in the cerebral cortex of manatees, in a region that Reep et al. (1989) called the "cluster cortex" to emphasize this feature. This peculiar cytoarchitecture has not been described in any other species, suggesting that it is a unique trait of the sirenia (Reep et al., 1989; Johnson et al., 1994).

\section{"General" connectivity}

It has been hypothesize that neurons receiving more synaptic inputs would have more complex dendritic trees, thereby increasing the distance between their cell bodies. By contrast, neurons receiving fewer inputs would have a less complex dendritic tree, allowing them to be more densely packed. According to Cragg (1967), this idea is based on the old histological studies of Franz Nissl (1860-1919) and Constantin Von Economo (1876-1931). Nissl (1898) pointed out that cortical neurons were more crowded in the mole and dog than in humans. Accordingly, von Economo (1926) proposed that the richer the fiber plexus was between neurons the more they would be separated, increasing the opportunity for neuronal interactions. Thus, the wider separation of neurons in humans compared to other species could be taken as an indication of a greater refinement of the connections between neurons. Hence, one way to compare possible differences in the microstructure of the cerebral cortex between different cortical layers, areas, or species is to estimate the average number of synaptic inputs per neuron. However, this ratio is rather coarse and it should be considered in terms of "general" connectivity ( $g c$ ratio) for the following two reasons. Firstly, the $g c$ ratio in a given layer is not an accurate estimate of the number of synaptic inputs received by neurons in that layer since dendrites, particularly of pyramidal cells, may cross several layers. Secondly, the origin of axon terminals in a given layer is multiple and uncharacterized (from local neurons and from neurons located in other layers or cortical areas, or in subcortical nuclei).

Bearing in mind these pitfalls, we have tested the hypothesis of the inverse relationship of the $g c$ ratio. We found that this principle in general held true in the human when compared with the rat and mouse, but not when comparing the rat with the mouse (Figure 12). Furthermore, when specific layers were compared, this rule was applicable to all layers in the rat, but not in the human or mouse. As shown in Figure 13, there are also remarkable laminar specific differences regarding the proportion, length, and density of putative excitatory and inhibitory synapses (asymmetric and 


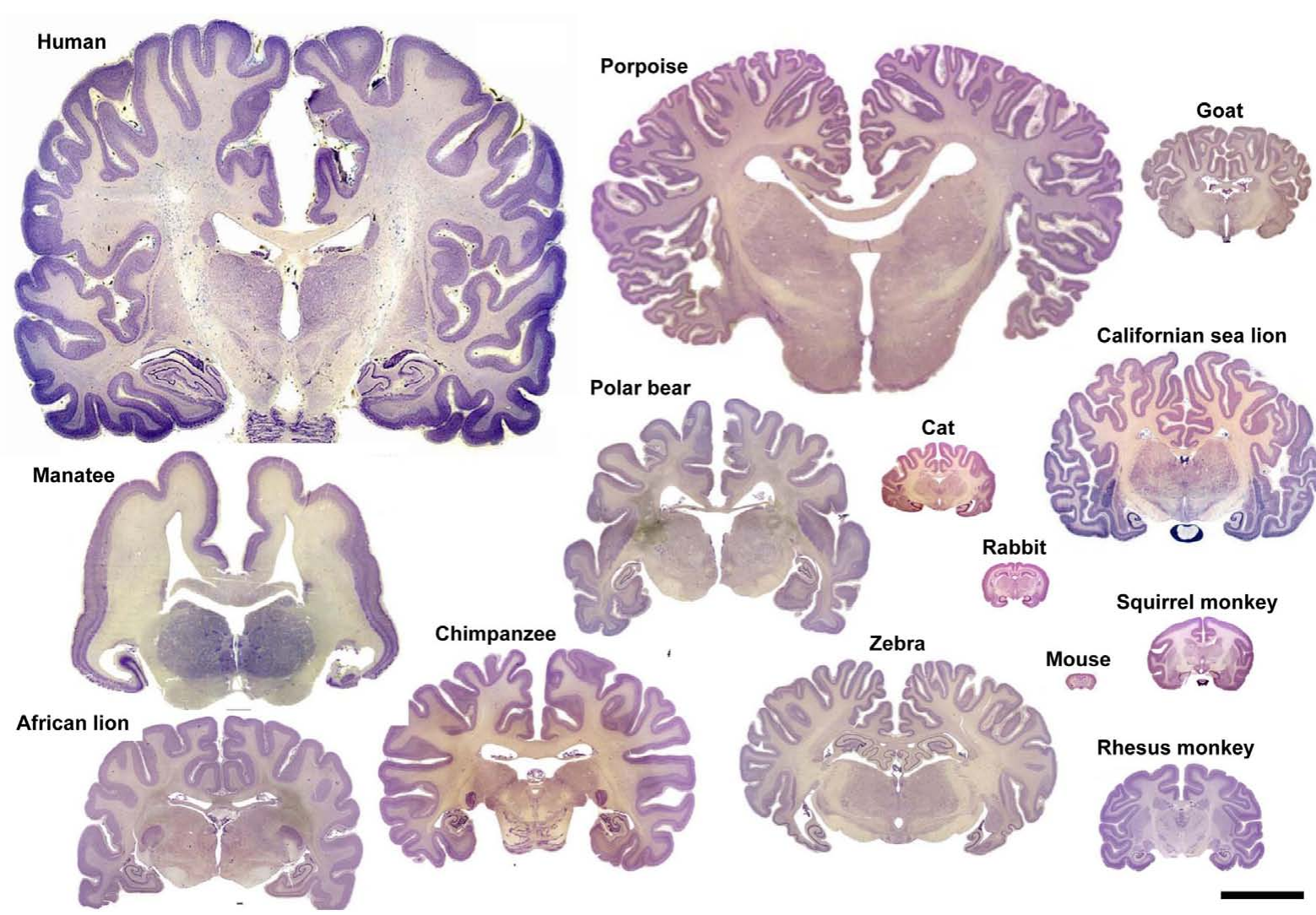

FIGURE 10 |Variation in brain size and patterns of convolutions. Coronal sections (25-40 $\mu \mathrm{m}$ thick; thionin staining) of the brain of several mammalian species. Adapted with permission from http://www.brains.rad.msu.edu, supported by the US National Science Foundation. Scale bar: $10 \mathrm{~cm}$.

symmetric synapses, respectively) between human, rat, and mouse, which did not necessarily affect the same layers. Thus, certain general features of cortical synaptology are applicable to the human, rat, and mouse, but there are also significant differences, which means that the pattern of synaptic organization is characteristic of each cortical area and species.

\section{Pyramidal cells: dendritic trees and spines}

Pyramidal cells are glutamatergic neurons located in all layers except layer I and they are the most abundant cortical neurons (estimated as $70-80 \%$ of the total neural population). These pyramidal cells represent the vast majority of projection neurons but their axons have intracortical collaterals that together with the cortico-cortical pyramidal cell axonal projections represent the main source of excitatory synapses in the cortex. The dendritic spines on pyramidal cells are the main postsynaptic target of excitatory synapses in the cerebral cortex and therefore, pyramidal cells are considered the principal neuronal building blocks of the cerebral cortex. However, the structure of pyramidal cells varies considerably between cortical areas and species in terms of the size and complexity of their dendritic arborization (the complexity of a dendritic arbor is evaluated as the total length of its dendritic branches along with the number and distribution of their branching points), in the density of dendritic spines on their dendritic branches and in the total number of dendritic spines (calculated by combining dendritic spine density and Sholl analysis: Elston et al., 2001, 2005; Jacobs et al., 2001; Ballesteros-Yáñez et al., 2010; for a review see Elston, 2007). For example, there is more than a 30 -fold difference in the total number of spines in the basal dendritic trees between populations of pyramidal cells in different cortical areas of the primate neocortex, whereas the pyramidal cells of the human prefrontal cortex have $72 \%$ more dendritic spines than those in the macaque prefrontal cortex, and approximately four times more dendritic spines than those in the prefrontal cortex of the squirrel monkey or mouse motor cortex. The mean density of spines on the dendritic branches is remarkably uniform in the mouse lateral cerebral cortex, yet the prelimbic/infralimbic field of the medial cortex stands out with a twofold higher density (Ballesteros-Yáñez et al., 2010). This difference, which is significant in the mouse, is modest when compared to the 10 -fold variation between cortical areas observed in primates, including humans (Elston, 2007). Furthermore, dendritic spines in humans have $100 \%$ more volume than those in the somatosensory cortex of mice (Figure 14) and in turn, these have $30 \%$ more volume than those in the visual/temporal cortex of this animal. Also, the length of the neck of the spines is significantly longer (about 30\%) in humans than in mice (Benavides-Piccione et al., 2002; Ballesteros-Yáñez et al., 2006).

These differences are critical for the functional processing of cortical information. For example, differences in the number of spines indicate differences in the number of excitatory inputs they 

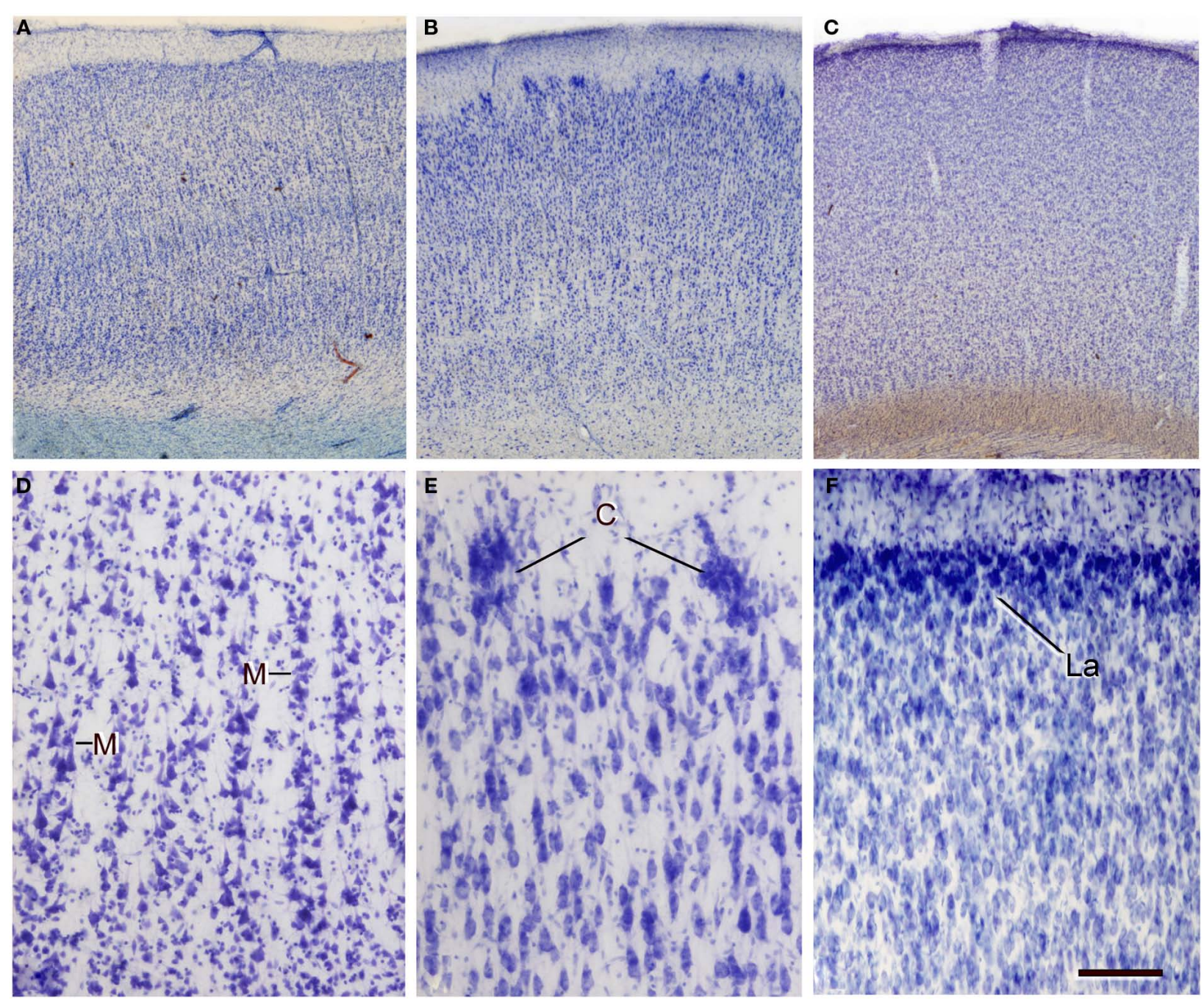

FIGURE 11 | Variations in neuron density, cytoarchitectonic organization, and in the size and distribution of vertical neuron aggregates. (A-C) Low-power photomicrographs of 100- $\mu \mathrm{m}$ thick vibratome sections stained with thionin from (A) Brodmann's area 21 of the human, (B) the occipital cortex of the giraffe, and (C) the bill representation in the primary

somatosensory cortex of the platypus. (D-F) High-power images showing some clear cytoarchitectonic differences between the three species: (D) presence of vertical aggregates of neurons or minicolumns (M) in layers II-III of the human area 39; (E) clusters of neurons (C) in layer II of the giraffe; (F) highly cellular dense layer II (La) in the platypus. Note the obvious differences in the density of cells between the three species. Scale bar in (F): $710 \mu \mathrm{m}$ in (A-C); $100 \mu \mathrm{m}$ in (D-F). receive, whereas the spine head volume is correlated with the area of the postsynaptic density. In turn, the size of the postsynaptic density is correlated with the number of presynaptic vesicles, the number of postsynaptic receptors and the ready-releasable pool of transmitter. The length of the spine neck is proportional to the extent of biochemical and electrical isolation of the spine from its parent dendrite. Differences in the total length, number of branches and the diameter of the dendrites affect the electrical, biochemical, and biophysical properties of the synaptic inputs of the pyramidal neuron (reviewed in Spruston, 2008; Kasai et al., 2010; Yuste, 2010). Therefore, variations in these parameters reflect differences in the complexity and information processing of cortical circuits between humans and other species, which probably have important implications for cognition, learning, and memory.

\section{Other studies: GABAergic interneurons}

GABAergic interneurons represent the vast majority of smooth or sparsely spiny non-pyramidal neurons or interneurons, which together with pyramidal cells and spiny non-pyramidal cells, represent the major classes of cortical neurons. The proportion of GABAergic neurons in the cortex of rodents is lower (in the rat no more than $15 \%$ of the total population of all cortical areas; e.g., Meinecke and Peters, 1987; Beaulieu, 1993; Micheva and Beaulieu, 1995; Gabbott et al., 1997) than in primates (up to 25 in most cortical areas of the monkey even reaching up to $34-44 \%$ in certain supragranular layers of the macaque and human; Hendry et al., 1987; Beaulieu et al., 1992; del Río and DeFelipe, 1996; Gabbott and Bacon, 1996). The differences in the proportion of GABAergic interneurons along with the existence of smooth interneurons in primates that are no found in rodents 

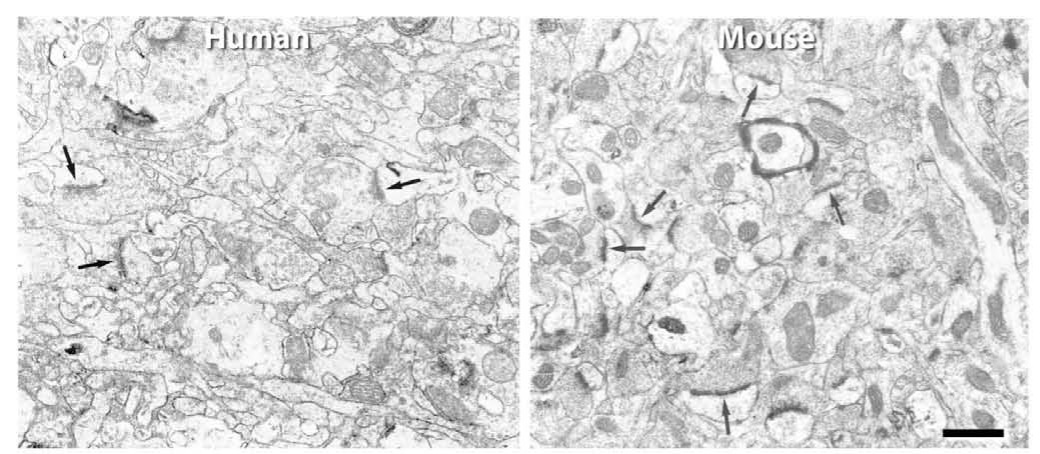

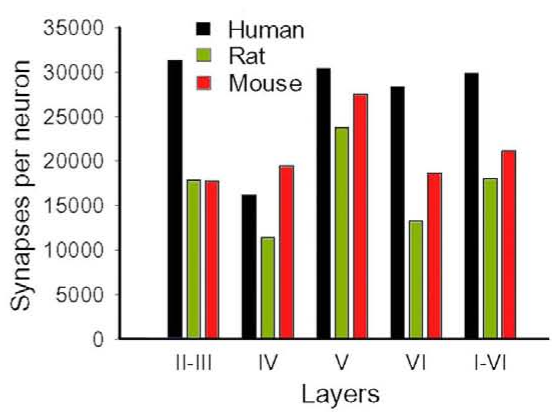

FIGURE 12 | Electron microscopy and number of synapses per neuron. Left, Electron micrographs illustrating the neuropil of layer IIla in the human temporal cortex, and of layer III of the mouse barrel cortex. Note the higher density of synapses (some of them indicated by arrows) in the mouse cortex. Scale bar $=0.5 \mu \mathrm{m}$. Right, Number of synapses per neuron in the human, rat, and mouse. The values obtained in layers II, IIla, and IIIb of human, and layers Va and Vb of rat were recalculated according to the relative thickness of these layers to estimate the representative values of layers II-III and V, respectively. From DeFelipe et al. (2002).

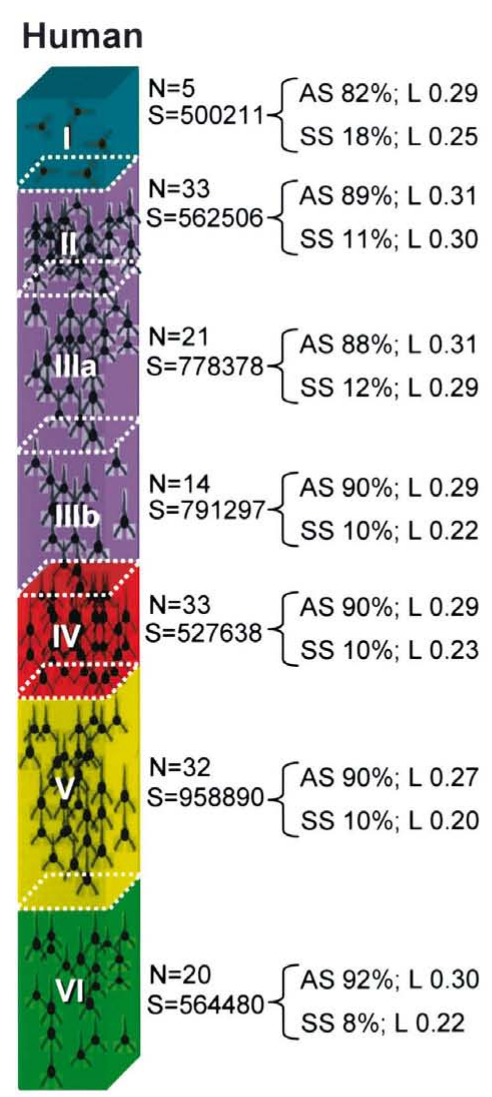

Cortical thickness $=2622 \mu \mathrm{m}$

Neurons $(\mathrm{N})=158$

Synapses $(S)=4683400$

AS synapses $=89 \% ; \mathrm{L} 0.30 \mu \mathrm{m}$

SS synapses $=11 \% ; L \quad 0.25 \mu \mathrm{m}$

$\mathrm{N}^{\circ}$ synapses/neuron $(\mathrm{S} / \mathrm{N})=29642$
Rat

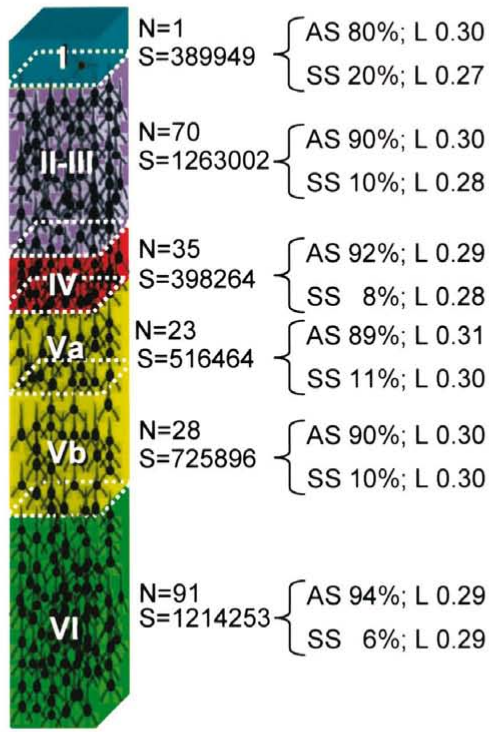

Cortical thickness $=1827 \mu \mathrm{m}$

Neurons $(\mathrm{N})=249$

Synapses $(S)=4507828$

AS synapses $=89 \% ; \mathrm{L} 0.30 \mu \mathrm{m}$

SS synapses $=11 \% ; L \quad 0.28 \mu \mathrm{m}$

$\mathrm{N}^{\circ}$ synapses/neuron $(\mathrm{S} / \mathrm{N})=18104$
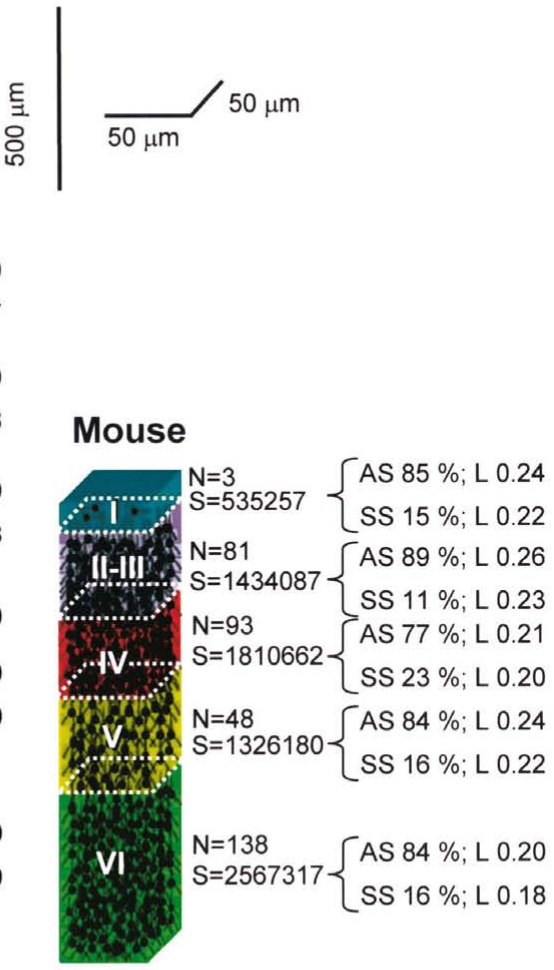

Cortical thickness $=1210 \mu \mathrm{m}$

Neurons $(\mathrm{N})=364$

Synapses $(S)=7673503$

AS synapses $=84 \% ; \mathrm{L} 0.23 \mu \mathrm{m}$

SS synapses $=16 \% ; \quad L \quad 0.21 \mu \mathrm{m}$

$\mathrm{N}^{\circ}$ synapses/neuron $(\mathrm{S} / \mathrm{N})=21081$
FIGURE 13 | Cortical microanatomical variations between humans, rats, and mice. Comparison of the thickness of layers, number of neurons and of the synaptic profiles within cubes of cortical tissue $(50 \mu \mathrm{m}$ wide by $50 \mu \mathrm{m}$ thick) from the pial surface to the white matter in the human (anterolateral temporal cortex; T2-T3), rat (hindlimb area of the somatosensory cortex), and mouse (barrel cortex). L, cross-sectional length of synaptic junctions; AS, asymmetric synapses; SS, symmetric synapses. Values taken from DeFelipe et al. (2002). 

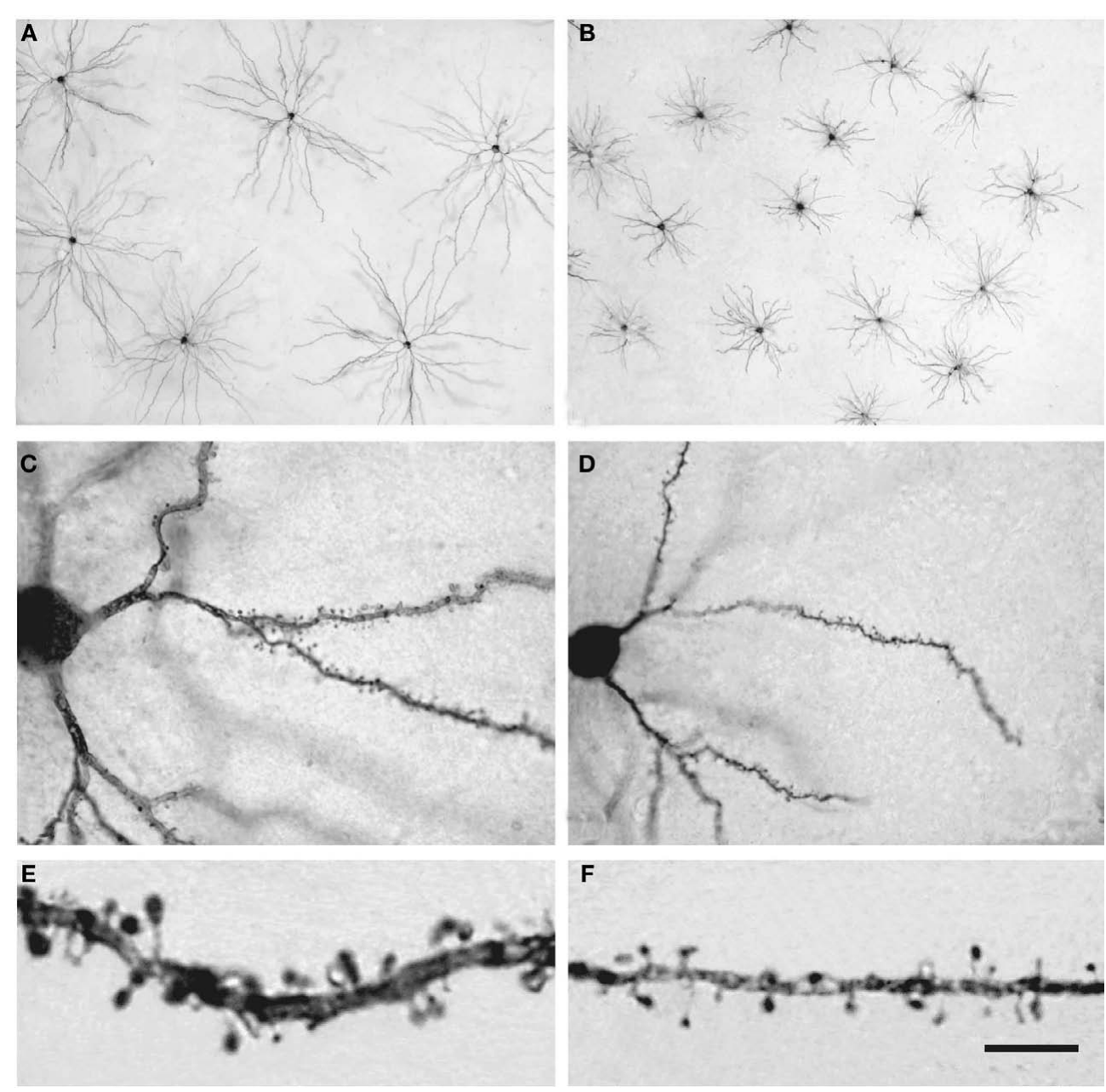

FIGURE 14 | Pyramidal cells in the human and mouse neocortex. (A,B) Low-power photomicrographs of layer III pyramidal cells injected with Lucifer Yellow and processed with DAB in human $(\mathbf{A})$ and mouse $(\mathbf{B})$ temporal cortex. Note the smaller size of mouse cells. The section is parallel to the cortical surface. (C,D): Photomicrograph of horizontally projecting dendrites of a human
(C) and mouse (D) pyramidal cell. (E,F): High-power photomicrographs of the basal dendritic segments of human (E) and mouse (F) pyramidal cells illustrating dendritic spines. Note the smaller size of the mouse spines. Scale bar in (F): $425 \mu \mathrm{m}$ in (A,B); $45 \mu \mathrm{m}$ in (C,D); $10 \mu \mathrm{m}$ in (E,F). Taken from Benavides-Piccione et al. (2002).
(Hof et al., 2000; DeFelipe et al., 2002; Raghanti et al., 2010), and the demonstration of differences in the developmental origins of the GABAergic interneurons in rodents and primates, including humans (Letinic et al., 2002; Rakic and Zecevic, 2003; Petanjek et al., 2009; Jakovcevski et al., 2011; reviewed in Bystron et al., 2008; Jones, 2009; Rakic, 2009), seems to indicate that in the course of evolution of the primate cortex more GABA neurons and newer forms of GABA interneurons have appeared (DeFelipe et al., 2002).

A remarkable example of this diversification is the so called double bouquet cell, characterized by its long descending, vertically bundled axon, which crosses several cortical layers, generally termed "bundles" or "horse-tails" (Figure 15).

These cells were originally described by Cajal (1899) as a prominent feature of the human cortex and later, they were discovered in monkeys as well and named type 3 (Jones, 1975), cells with horse-tail-shaped axons (Szentágothai, 1975), or cells with axons forming vertical bundles (Valverde, 1978). Double bouquet cells are very numerous and regularly distributed (Figure 16) in primates, but they do not appear to exist in rodents or lagomorphs, and they are only present in some carnivores (Ballesteros-Yánez et al., 2005). These cells are the source of a large number of GABAergic synapses on small dendritic shafts and dendritic spines on oblique dendrites of pyramidal cells within a very narrow column of cortical tissue (DeFelipe et al., 1990; Peters and Sethares, 1997). Furthermore, it has been shown that the radial fasciculi (bundles of myelinated axons originated from vertical aggregates of pyramidal cells or pyramidal cell modules), and double bouquet axons, overlap on a one-to-one basis in the monkey and human (del Río and DeFelipe, 1997; Peters and Sethares, 1997; Ballesteros-Yánez et al., 2005). In rodents, all or almost all cortical GABAergic interneurons arise from the ganglionic eminence at the base of the developing cerebral hemisphere, while in monkeys and humans a significant number are born in the neuroepithelium of the lateral ventricular wall as well (reviewed in Anderson et al., 2002; Xu et al., 2003; Jones, 2009; Rakic, 2009). Hence, double bouquet cells may migrate radially, 
which might be a mechanism by which the complementary microcolumnar organization of double bouquet cells and pyramidal cell modules originated in the neocortex of primates (DeFelipe, 2002).

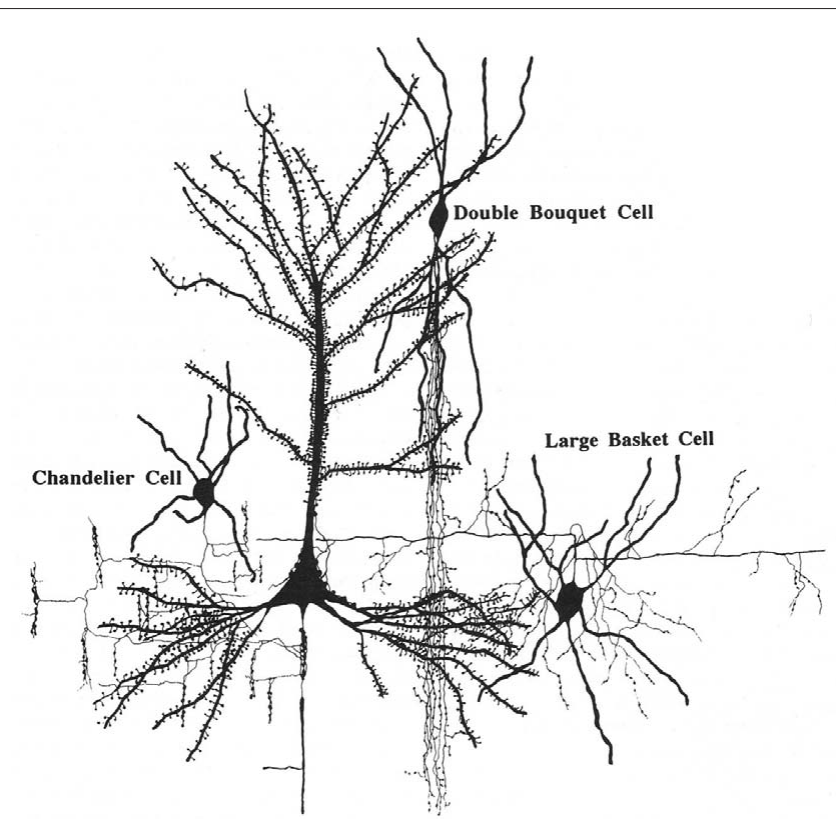

FIGURE 15 | Synaptic relationships between double bouquet cells, chandelier cells, and large basket cells with pyramidal cells. These cells constitute the best morphologically and chemically characterized types of interneurons. From DeFelipe and Fariñas (1992).
As a consequence, while double bouquet cells may be considered a key element in the microcolumnar organization of primates, this is not necessarily the case in other mammalian species. Differences in the abundance and distribution of double bouquet cells appear to reflect fundamental differences in the cortical microorganization between primates and other species.

Another interesting but little known example of clear differences in the neuronal composition between humans and other species are the interneurons expressing tyrosine hydroxylase $(\mathrm{TH})$, the rate limiting enzyme in catecholamine synthesis (Figure 17). For example, $\mathrm{TH}$ interneurons are found abundantly in layers $\mathrm{V}-\mathrm{VI}$ and the subadjacent white matter in many human cortical areas (Benavides-Piccione and DeFelipe, 2007), whereas they are absent in the cortex of great apes (chimpanzee, bonobo, gorilla, and orangutan; Raghanti et al., 2009). However, in Old World monkeys (golden guenon, patas monkey, olive baboon, moor macaque, black and white colobus, and François' langur) TH neurons are also present in layers $\mathrm{V}$ and VI, and in the subjacent white matter in some cortical areas (Kohler et al., 1983; Lewis et al., 1988; Benavides-Piccione and DeFelipe, 2007; Raghanti et al., 2009). In the neocortex of certain cetaceans, TH neurons are mainly confined to layer I (Hof et al., 1995), while the relatively few TH neurons in the rat can be found in all cortical layers, yet they are most abundant in layers II-III. In addition, the majority of TH neurons in the rat cortex are GABAergic (Kosaka et al., 1987), whereas only about $50 \%$ are GABAergic in the human neocortex (Gaspar et al., 1987; Hornung et al., 1989; Kuljis et al., 1989; Trottier et al., 1989). Therefore, TH neurons seem to be a special type of interneuron particularly abundant in the deep cortical layers of the human
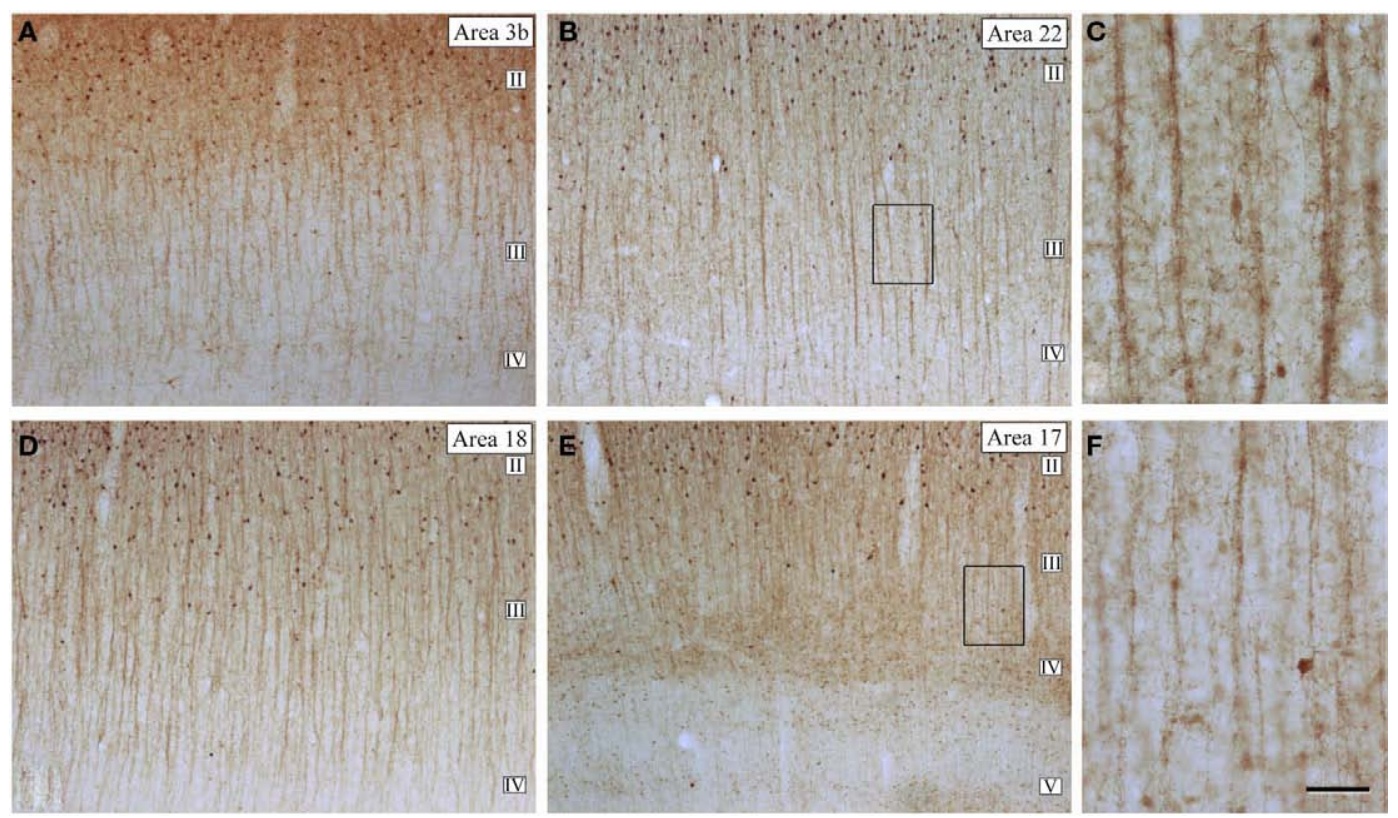

FIGURE 16 | Microcolumnar organization of double bouquet cells. $(A, B, D, E)$ Low magnification photomicrographs of calbindin immunostained (CB-ir) sections from the human: primary somatosensory (area 3b); temporal associative (area 22); and primary (area 17) and secondary (area 18) visual areas, showing the distribution of CB-ir cell bodies and double bouquet cell horse-tails. Note the large number and the regular distribution of double bouquet cell horse-tails. (C,F) High magnification of the boxed areas shown in (B,E), respectively, to highlight the differences in thickness, density, and number of axon collaterals of CB-ir double bouquet cell horse-tails in different cortical areas. Scale bar: $150 \mu \mathrm{m}$ in $(\mathbf{A}, \mathbf{B}, \mathbf{D}, \mathbf{E})$; $45 \mu \mathrm{m}$ in (C-F). Adapted from Ballesteros-Yánez et al. (2005). 

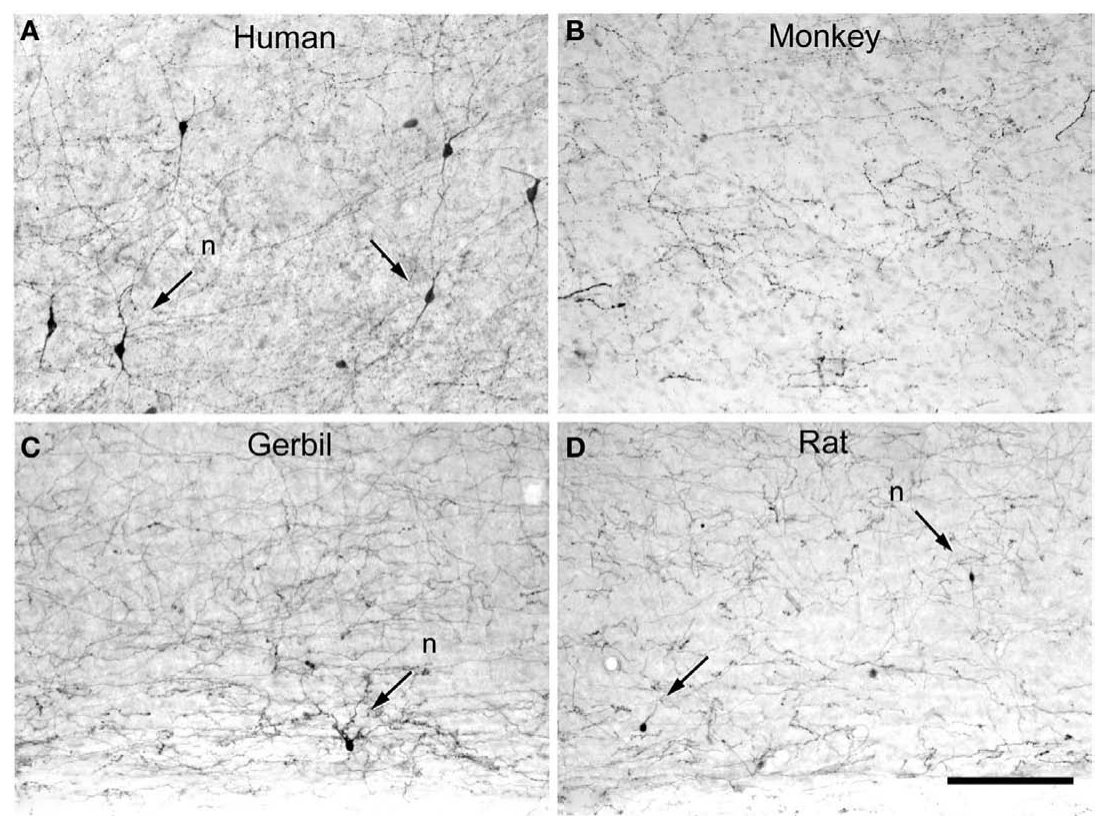

FIGURE 17 |Tyrosine hydroxylase interneurons. Low-power photomicrographs of tyrosine hydroxylase $(\mathrm{TH})$ immunostaining in the temporal cortex of the human (anterolateral temporal lobe) (A), macaque (area TE) (B), somatosensory cortex of the gerbil (C), and somatosensory cortex of rat (D), extending from lower part of layer $V$ to the white matter. Some TH neurons are indicated with arrows. TH neurons are relatively abundant in the deep layers of the human neocortex when compared to other species. However, they are occasionally found in the somatosensory cortex of the rat and gerbil whereas in the macaque monkey no TH neurons were observed in the in the lateral temporal cortex. Nevertheless, in other cortical areas of the monkey these cells are also present in deep layers. Scale bar $=160 \mu \mathrm{m}$. neocortex. As interneurons are involved in shaping the activity of pyramidal neurons, and pyramidal neurons also show distinctive species-specific attributes, all these differences contribute to distinct information processing of characteristic of the human brain.

To conclude, the human cerebral cortex is unique in many aspects and it is likely that as more detailed studies are carried out on human cortical circuits (DeFelipe, 2010b), we will discover many more differences at the genetic, molecular, structural, and physiological levels between humans and other species. Thus, not only the increase in size, and therefore in complexity, of our brains seems to be responsible for our higher or more abstract mental abilities but also, the specialization of our cortical circuits appears to be critical.

\section{REFERENCES}

Anderson, S. A., Kaznowski, C. E., Horn,

C., Rubenstein, J. L., and McConnell,

S. K. (2002). Distinct origins of neocortical projection neurons and interneurons in vivo. Cereb. Cortex 12, 702-709.

Ballesteros-Yáñez, I., Benavides-Piccione, R., Bourgeois, J. P., Changeux, J. P., and DeFelipe, J. (2010). Alterations of cortical pyramidal neurons in mice lacking high-affinity nicotinic receptors. Proc. Natl. Acad. Sci. U.S.A. 107, 11567-11572.

Ballesteros-Yáñez, I., BenavidesPiccione, R., Elston, G. N., Yuste, R., and DeFelipe, J. (2006). Density and morphology of dendritic spines in mouse neocortex. Neuroscience 138, 403-409.

Ballesteros-Yánez, I., Muñoz, A., Contreras, J., Gonzalez, J., RodriguezVeiga, E., and DeFelipe, J. (2005). The double bouquet cell in the human other mammals. J. Comp. Neurol.486, 344-360.

Balter, M. (2009). On the origin of art and symbolism. Science 323, 709-711.

Barton, R. A. (2002). How did brains evolve? Nature 415, 134-135.

Barton, R. A., and Harvey, P. H. (2000). Mosaic evolution of brain structure in mammals. Nature 405, 1055-1058. cerebral cortex and a comparison with

\section{ACKNOWLEDGMENTS}

I am very grateful to the members of my laboratory: Lidia AlonsoNanclares, Lidia Blázquez-Llorca, Ruth Benavides-Piccione, Isabel Fernaud, Ana García, Juncal González, Asta Kastanauskaite, Guillermo Lapuente, Gonzalo León, Ángel Merchán, Paula Merino, Miguel Miguens, Alberto Muñoz, José Rodrigo-Rodríguez, and Lorena Valdés for their support and assistance. This work was supported by grants from the following entities: Centre for Networked Biomedical Research into Neurodegenerative Diseases (CIBERNED, CB06/05/0066), Fundación CIEN, and the Spanish Ministry of Education, Science and Innovation (grant SAF200909394 and Cajal Blue Brain Project).

Beaulieu, C. (1993). Numerical data on neocortical neurons in adult rat, with special reference to the GABA population. Brain Res. 609, 284-292.

Beaulieu, C., and Colonnier, M. (1989). Number and size of neurons and synapses in the motor cortex of cats raised in different environmental complexities. J. Comp. Neurol. 289, 178-181.

Beaulieu, C., Kisvarday, Z., Somogyi, P., Cynader, M., and Cowey, A. (1992). Quantitative distribution of GABA-immunopositive and -immunonegative neurons and synapses in the monkey striate cortex (area 17). Cereb. Cortex 2, 295-309.
Benavides-Piccione, R., Ballesteros-Yañez, I., DeFelipe, J., and Yuste, R. (2002). Cortical area and species differences in dendritic spine morphology. J. Neurocytol. 31, 337-346.

Benavides-Piccione, R., and DeFelipe, J. (2007).Distribution of neurons expressing tyrosine hydroxylase in the human cerebral cortex. J. Anat. 211, 212-222.

Bermúdez de Castro, J. M. (2002). El chico de la Gran Dolina. Barcelona: Crítica.

Byrne, R. W., Barnard, P. J., Davidson, I., Janik, V.M., McGrew, W.C., Miklósi,A., and Wiessner,P.(2004).Understanding culture across species. Trends Cogn. Sci. (Regul. Ed.) 8, 341-346. 
Bystron, I., Blakemore, C., and Rakic, P. (2008). Development of the human cerebral cortex: Boulder Committee revisited. Nat. Rev. Neurosci. 9, 110-122.

Cajal, S. R. (1899). Estudios sobre la corteza cerebral humana I: corteza visual. Rev. Trim. Microgr. 4, 1-63. Translated in: DeFelipe, J., and Jones, E. G. (1988). Cajal on the Cerebral Cortex. New York: Oxford University Press.

Cajal, S. R. (1917). Recuerdos de Mi Vida, Vol. 2, Historia de Mi Labor Científica. Madrid: Moya.

Campbell, M. C., and Tishkoff, S. A. (2008). African genetic diversity: implications for human demographic history, modern human origins, and complex disease mapping. Annu. Rev. Genomics Hum. Genet. 9 , 403-433.

Clark, D. A., Mitra, P. P., and Wang, S. S. (2001). Scalable architecture in mammalian brains. Nature 411, 189-193.

Conard, N. J. (2010). Cultural modernity: consensus or conundrum? Proc. Natl. Acad. Sci. U.S.A. 107, 7621-7622.

Conel, J., and Le, R. (1941). The Postnatal Development of the Human Cerebral Cortex. Vol. 2. The Cortex of the One-Month Infant. Cambridge, MA: Harvard University Press.

Conel, J., and Le, R. (1967). The Postnatal Development of the Human Cerebral Cortex. Vol. 8. The Cortex of the SixYear Child. Cambridge, MA: Harvard University Press.

Couzin, I. D. (2009). Collective cognition in animal groups. Trends Cogn. Sci. (Regul. Ed.) 13, 36-43.

Cragg, B. G. (1967). The density of synapses and neurones in the motor and visual areas of the cerebral cortex. J. Anat. 101, 639-654.

de Winter, W., and Oxnard, C. E. (2001). Evolutionary radiations and convergences in the structural organization of mammalian brains. Nature 409, 710-714.

DeFelipe, J. (2002). Cortical interneurons: from Cajal to 2001. Prog. Brain Res. 136, 215-238.

DeFelipe, J. (2006). Brain plasticity and mental processes: Cajal again. Nat. Rev. Neurosci. 7, 811-817.

DeFelipe, J. (2010a)."Reflexiones sobrelo bello, el arte y la evolución del cerebro," in Neuroestética, ed. A. Martín Araguz (Madrid: Saned), 51-76.

DeFelipe, J. (2010b). From the connectome to the synaptome: an epic love story. Science 330, 1198-1201.

DeFelipe, J., Alonso-Nanclares, L., and Arellano, J. I. (2002). Microstructure of the neocortex: comparative aspects. J. Neurocytol. 31, 299-316.

DeFelipe, J., and Fariñas, I. (1992). The pyramidal neuron of the cerebral cortex: morphological and chemical characteristics of the synaptic inputs. Prog. Neurobiol. 39, 563-607.

DeFelipe, J., Hendry, S. H., Hashikawa, T., Molinari, M., and Jones, E. G. (1990). A microcolumnar structure of monkey cerebral cortex revealed by immunocytochemical studies of double bouquet cell axons. Neuroscience 37, 655-673

del Río, M. R., and DeFelipe, J. (1996). Colocalization of calbindin D-28k, calretinin, and GABA immunoreactivities in neurons of the human temporal cortex. J. Comp. Neurol.369, 472-482.

del Río, M. R., and DeFelipe, J. (1997). Double bouquet cell axons in the human temporal neocortex: relationship to bundles of myelinated axons and colocalization of calretinin and calbindin D-28k immunoreactivities. J. Chem. Neuroanat. 13, 243-251.

Dexler, H. (1913). Das Hirn von Halicore dugong Erxl. Gegenbaurs. Morphol. Jahrb. 45, 97-190.

Elston, G. N. (2007). "Specializations of the neocortical pyramidal cell during primate evolution," in Evolution of the Nervous Systems: A Comprehensive Reference, Vol. 4 Primates, eds J. H. Kaas and T. M. Preuss (Amsterdam: Elsevier), 191-242.

Elston, G. N., Benavides-Piccione, R., and DeFelipe, J. (2001). The pyramidal cell in cognition: a comparative study in man and monkey. J. Neurosci. 21, 1-5.

Elston, G. N., Elston, A., Casagrande, V. A., and Kaas, J. (2005). Pyramidal neurons of granular prefrontal cortex the galago: complexity in the evolution of the psychic cell in primates. Anat. Rec. 285, 610-618;

Finlay, B. L., and Darlington, R. B. (1995). Linked regularities in the development and evolution of mammalian brains. Science 268, 1578-1584.

Gabbott, P. L., and Bacon, S. J. (1996). Local circuit neurons in the medial prefrontal cortex (areas 24a,b,c, 25 and 32 ) in the monkey: II. Quantitative areal and laminar distributions. J. Comp. Neurol. 364, 609-636.

Gabbott, P. L., Dickie, B. G., Vaid, R. R., Headlam, A. J., and Bacon, S. J. (1997). Local-circuit neurones in the medial prefrontal cortex (areas 25, 32 and 24b) in the rat: morphology and quantitative distribution. J. Comp. Neurol. 377, 465-499.

Gaspar, P., Berger, B., Febvret, A., Vigny, A., Krieger-Poulet, M., and BorriVoltattorni, C. (1987). Tyrosine hydroxylase-immunoreactive neurons in the human cerebral cortex: a novel catecholaminergic group? Neurosci. Lett. 80, 257-262.

Glezer, I. I., Hof, P. R., Leranth, C., and Morgane, P. J. (1993). Calcium- binding protein-containing neuronal populations in mammalian visual cortex: a comparative study in whales, insectivores, bats, rodents, and primates. Cereb. Cortex 3, 249-272.

Glezer, I. I., Jacobs, M. S., and Morgane, P. J. (1988). Implications of the "initial brain" concept for brain evolution in Cetacea. Behav. Brain Sci. 11, 75-116.

Haug, H. (1987). Brain sizes, surfaces, and neuronal sizes of the cortex cerebri: a stereological investigation of man and his variability and a comparison with some mammals (primates, whales, marsupials, insectivores, and one elephant). Am. J. Anat. 180, 126-142.

Hendry, S. H., Schwark, H. D., Jones, E. G. and Yan, J. (1987). Numbers and proportions of GABA-immunoreactive neurons in different areas of monkey cerebral cortex. J. Neurosci. 7 , 1503-1519.

Henshilwood, C.S., d'Errico, F., and Watts, I. (2009). Engraved ochres from the Middle Stone Age levels at Blombos cave, South Africa. J. Hum. Evol. 57, 27-47.

Henshilwood, C. S., d'Errico, F., Yates, R., Jacobs, Z., Tribolo, C., Duller, G. A., Mercier, N., Sealy, J. C., Valladas, H., Watts, I., and Wintle, A. G. (2002). Emergence of modern human behavior: Middle Stone Age engravings from South Africa. Science 295 , 1278-1280.

Hof, P. R., Glezer, I. I., Conde, F., Flagg, R. A., Rubin, M. B., Nimchinsky, E. A., and Vogt Weisenhorn, D. M. (1999). Cellular distribution of the calciumbinding proteins parvalbumin, calbindin, and calretinin in the neocortex of mammals: phylogenetic and developmental patterns. J. Chem. Neuroanat. 16, 77-116.

Hof, P. R., Glezer, I. I., Revishchin, A. V., Bouras, C., Charnay, Y., and Morgane, P. J. (1995). Distribution of dopaminergic fibers and neurons in visual and auditory cortices of the harbor porpoise and pilot whale. Brain Res. Bull. $36,275-284$.

Hof, P. R., Glezer, L. I., Nimchinsky, E. A., and Erwin, J. M. (2000). Neurochemical and cellular specializations in the mammalian neocortex reflect phylogenetic relationships: evidence from primates, cetaceans, and artiodactyls. Brain Behav. Evol. 55, 300-310.

Holloway, R. (1996). "Evolution of the human brain" in Handbook of Human Symbolic Evolution, eds A. Lock and C. R. Peters (Oxford: Oxford University Press), 74-125.

Hornung, J. P., Tork, I., and De Tribolet, N. (1989). Morphology of tyrosine hydroxylase-immunoreactive neu- rons in the human cerebral cortex. Exp. Brain Res. 76, 12-20.

Jacobs, B., Schall, M., Prather, M., Kapler, L., Driscoll, L., Baca, S., Jacobs, J., Ford, K., Wainwright, M., and Treml, M. (2001). Regional dendritic and spine variation in human cerebral cortex: a quantitative study. Cereb. Cortex 11, 558-571.

Jakovcevski, I., Mayer, N., and Zecevic, N. (2011). Multiple origins of human neocortical interneurons are supported by distinct expression of transcription factors. Cereb. Cortex. doi: 10.1093/cercor/bhq245. [Epub ahead of print].

Jerison, H. J. (1973). Evolution of the Brain and Intelligence. New York: Academic Press.

Johnson, J. I., Kirsch, J. A., Reep, R. L., and Switzer, R. C. III. (1994). Phylogeny through brain traits: more characters for the analysis of mammalian evolution. Brain Behav. Evol. 43, 319-347.

Jones, E. G. (1975). Varieties and distribution of non-pyramidal cells in the somatic sensory cortex of the squirrel monkey. J. Comp. Neurol. 160, 205-268.

Jones, E. G. (2009). Origins of cortical interneurons: mouse vs monkey and human. Cereb. Cortex 19, 1953-1956.

Kaas, J. H., and Collins, C. E. (2001). Evolving ideas of brain evolution. Nature 411, 141-142.

Kasai, H., Fukuda, M., Watanabe, S., Hayashi-Takagi, A., and Noguchi, J. (2010). Structural dynamics of dendritic spines in memory and cognition. Trends Neurosci. 33, 121-129.

Katz, P. S., and Harris-Warrick, R. M. (1999). The evolution of neuronal circuits underlying species-specific behavior. Curr. Opin. Neurobiol. 9, 628-633.

Klein, R.G. (2009). Darwin and the recent African origin of modern humans. Proc. Natl. Acad. Sci. U.S.A. 106 16007-16009.

Kohler, C., Everitt, B. J., Pearson, J., and Goldstein, M. (1983). Immunohistochemical evidence for a new group of catecholamine- containing neurons in the basal forebrain of the monkey. Neurosci. Lett. 37, 161-166.

Kosaka, T., Kosaka, K., Hataguchi, Y., Nagatsu, I., Wu, J. Y., Ottersen, O. P., Storm-Mathisen, J., and Hama, K. (1987). Catecholaminergic neurons containing GABA-like and/ or glutamic acid decarboxylase-like immunoreactivities in various brain regions of the rat. Exp. Brain Res. 66, 191-210.

Kuljis, R. O., Martin-Vasallo, P., and Peress, N. S. (1989). Lewy bodies in tyrosine hydroxylase-synthesizing neurons of 
the human cerebral cortex. Neurosci. Lett. 106, 49-54.

Letinic, K., Zoncu, R., and Rakic, P. (2002). Origin of GABAergic neurons in the human neocortex. Nature 417, 645-649.

Lewis, D. A., Foote, S. L., Goldstein, M., and Morrison, J. H. (1988). The dopaminergic innervation of monkey prefrontal cortex: a tyrosine hydroxylase immunohistochemical study. Brain Res. 449, 225-243.

Marino, L. (1998). A comparison of encephalization between odontocete cetaceans and anthropoid primates. Brain Behav. Evol. 51, 230-238.

Mcbrearty, S., and Brooks, A. S. (2000). The revolution that wasn't: a new interpretation of the origin of modern human behavior. J. Hum. Evol. 39, 453-563.

McDougall, I., Brown, F. H., and Fleagle, J. G. (2005). Stratigraphic placement and age of modern humans from Kibish, Ethiopia. Nature 433, 733-736.

Meinecke, D. L., and Peters, A. (1987). GABA immunoreactive neurons in rat visual cortex. J. Comp. Neurol. 261, 388-404.

Micheva, K. D., and Beaulieu, C. (1995). Postnatal development of GABA neurons in the rat somatosensory barrel cortex: a quantitative study. Eur. J. Neurosci. 7, 419-430.

Nissl, F. (1898). Nervenzellen und graue Substanz. Munch. med. Wschr. 45, 988-992, 1023-1029, 1060-1062.

Petanjek, Z., Kostović, I., and Esclapez, M. (2009). Primate-specific origins and migration of cortical GABAergic neurons. Front. Neuroanat. 3:26. doi: 10.3389/neuro.05.026.2009

Peters, A., and Sethares, C. (1997). The organization of double bouquet cells in monkey striate cortex. J. Neurocytol. 26, 779-797.

Preuss, T. M., and Coleman, G. Q. (2002). Human-specific organi- zation of primary visual cortex: alternating compartments of dense Cat-301 and calbindin immunoreactivity in layer 4A. Cereb. Cortex 12, 671-691.

Raghanti, M. A., Spocter, M. A., Butti, C., Hof, P.R., and Sherwood, C. C. (2010). A comparative perspective on minicolumns and inhibitory GABAergic interneurons in the neocortex. Front. Neuroanat. 4:3. doi: 10.3389/ neuro.05.003.2010

Raghanti, M.A., Spocter, M.A., Stimpson, C.D., Erwin, J. M., Bonar, C. J., Allman, J. M., Hof, P. R., and Sherwood, C. C. (2009). Species-specific distributions of tyrosine hydroxylase-immunoreactive neurons in the prefrontal cortex of anthropoid primates. Neuroscience 158, 1551-1559.

Rakic, P. (2009). Evolution of the neocortex: a perspective from developmental biology. Nat. Rev. Neurosci. 10, 724-735.

Rakic, S., and Zecevic, N. (2003). Emerging complexity of layer I in human cerebral cortex. Cereb. Cortex 13, 1072-1083.

Reep, R. L., Johnson, J. I., Switzer, R. C., and Welker, W. I. (1989). Manatee cerebral cortex: cytoarchitecture of the frontal region in Trichechus manatus latirostris. Brain Behav. Evol. 34, 365-386.

Rockel, A. J., Hiorns, R. W., and Powell, T. P. (1980). The basic uniformity in structure of the neocortex. Brain 103, 221-244.

Rockland, K. S. (2010). Five points on columns. Front. Neuroanat. 4:22. doi: 10.3389/fnana.2010.00022

Roth, G., and Dicke, U. (2005). Evolution of the brain and intelligence. Trends Cogn. Sci. (Regul. Ed.) 9, 250-257.

Skoglund, T.S., Pascher, R., and Berthold, C. H. (1996). Heterogeneity in the columnar number of neurons in dif- ferent neocortical areas in the rat. Neurosci. Lett. 208, 97-100.

Spitzka, E.A. (1907).A study of the brains of six eminent scientist and scholars belonginig to the american anthropometric society, together with a description of the skull of professor E. D. Cope. (1907). Trans. Am. Soc 21, 175-308.

Spruston, N. (2008). Pyramidal neurons: dendritic structure and synaptic integration. Nat. Rev. Neurosci. 9 , 206-221.

Sterio, J. (1984). The unbiased estimation of number and sizes of arbitrary particles using the dissector. J. Microsc. 134, 127-136.

Stolzenburg, J. U., Reichenbach, A., and Neumann, M. (1989). Size and density of glial and neuronal cells within the cerebral neocortex of various insectivorian species. Glia 2, 78-84.

Sultan, F. (2002). Analysis of mammalian brain architecture. Nature 415, 133-134.

Szentágothai, J. (1975). The'module-concept' in cerebral cortex architecture. Brain Res. 95, 475-496.

Texier, P. J., Porraz, G., Parkington, J., Rigaud, J. P., Poggenpoel, C., Miller, C., Tribolo, C., Cartwright, C., Coudenneau, A., Klein, R., Steele, T., and Verna, C. (2010). A Howiesons Poort tradition of engraving ostrich eggshell containers dated to 60,000 years ago at Diepkloof Rock Shelter, South Africa. Proc. Natl. Acad. Sci. U.S.A. 107, 6180-6185.

Trottier, S., Geffard, M., and Evrard, B. (1989). Co-localization of tyrosine hydroxylase and GABA immunoreactivities in human cortical neurons. Neurosci. Lett. 106, 76-82.

Valverde, F. (1978). The organization of area 18 in the monkey. A golgi study. Anat. Embryol. 154, 305-334.

von Economo, C. (1926). Ein Koeffizient fur die Organisationshohe der
Grosshirnrinde. Klin. Wsch. 5, 593-595.

Wang, Y., Brzozowska-Prechtl, A., and Karten, H. J. (2010). Laminar and columnar auditory cortex in avian brain. Proc. Natl. Acad. Sci. U.S.A. 107, 12676-12681.

Wilder,B.G.(1911).Exhibition of, and preliminary note upon, a brain of about one-half the average size from a white man of ordinary weight and intelligence. J. Nerv. Ment. Dis. 38, 95-97.

$\mathrm{Xu}, \mathrm{Q}$., de la Cruz, E., and Anderson, S. A. (2003). Cortical interneuron fate determination: diverse sources for distinct subtypes? Cereb. Cortex 13, 670-676.

Yopak, K. E., Lisney, T. J., Darlington, R. B., Collin, S. P., Montgomery, J. C., and Finlay, B. L. (2010). A conserved pattern of brain scaling from sharks to primates. Proc. Natl. Acad. Sci. U.S.A. 107, 12946-12951.

Yuste, R. (2010). Dendritic Spines. Cambridge, MA: MIT Press.

Conflict of Interest Statement: The author declares that the research was conducted in the absence of any commercial or financial relationships that could be construed as a potential conflict of interest.

Received: 06 April 2011; paper pending published: 23 April 2011; accepted: 01 May 2011; published online: 16 May 2011. Citation: DeFelipe J (2011) The evolution of the brain, the human nature of cortical circuits, and intellectual creativity. Front. Neuroanat. 5:29. doi: 10.3389/ fnana.2011.00029

Copyright $(2011$ DeFelipe. This is an openaccess article subject to a non-exclusive license between the authors and Frontiers Media $S A$, which permits use, distribution and reproduction in other forums, provided the original authors and source are credited and other Frontiers conditions are complied with. 